\title{
Tumour mutations in long noncoding RNAs enhance cell fitness
}

Roberta Esposito*1,2,3, Andrés Lanzós*1,2,4, Taisia Polidori 1,2, Hugo Guillen-Ramirez 5,6, Bernard Merlin 1,2, Lia Mela 1,2, Eugenio Zoni 2,9, Isabel Büchi 2,8, Lusine Hovhannisyan 2,7, Finn McCluggage 10,11, Matúš Medo 2,7, Giulia Basile 1,2, Dominik F. Meise 1,2, Sunandini Ramnarayanan 5,6, Sandra Zwyssig 1,2, Corina Wenger 1,2, Kyriakos Schwarz 1,2, Adrienne Vancura 1,2, Nuria Bosch-Guiteras 1,2,4, Marianna Kruithof-de Julio 2,9, Yitzhak Zimmer 2,7, Michaela Medová 2,7, Deborah Stroka 2,8, Archa Fox 10,11, Rory Johnson $1,2,5,6$

1.Department of Medical Oncology, Inselspital, Bern University Hospital, University of Bern, 3010 Bern, Switzerland. 2.Department for BioMedical Research, University of Bern, 3008 Bern, Switzerland

3.Institute of Genetics and Biophysics "Adriano Buzzati-Traverso", CNR, 80131 Naples, Italy.

4.Graduate School of Cellular and Biomedical Sciences, University of Bern, 3012 Bern, Switzerland.

5.School of Biology and Environmental Science, University College Dublin, Dublin D04 V1W8, Ireland.

6.Conway Institute for Biomolecular and Biomedical Research, University College Dublin, Dublin D04 V1W8, Ireland.

7.Department of Radiation Oncology, Inselspital, Bern University Hospital and University of Bern, Bern, Switzerland 8.University Clinic of Visceral Surgery and Medicine, Bern University Hospital, Inselspital, Department of Biomedical Research, University of Bern, Bern, Switzerland.

9.Department of Urology, Inselspital, Bern University Hospital, Bern, Switzerland.

10.School of Molecular Sciences, University of Western Australia, Crawley, Western Australia, Australia.

11.School of Human Sciences, University of Western Australia, Crawley, Western Australia, Australia.

* Equal contribution

Correspondence: rory.johnson@ucd.ie

Keywords: Cancer; Mutations; Long Non-Coding RNA; LncRNA; Cancer Driver Genes; PanCancer Analysis of Whole Genomes; CRISPR; NEAT1. 


\section{Abstract}

Tumour DNA contains thousands of single nucleotide variants (SNVs) in non-protein-coding elements, yet their functional significance remains poorly understood. Amongst the most highly mutated elements are long noncoding RNAs (IncRNAs), functional transcripts known to play key roles in carcinogenesis. Here, we investigate whether mutations in IncRNAs can act as "drivers" that promote cancer cell fitness. We develop an integrative driver IncRNA discovery algorithm and apply it to single nucleotide variants (SNVs) from 2583 primary tumours and 3527 metastases to reveal 54 potential "driver IncRNAs". Their relevance is supported by enrichment for previously-reported cancer genes, and by clinical and genomic features. Using knockdown and transgene overexpression experiments, we find that tumour SNVs in two novel IncRNAs can boost cell fitness. Driver analysis confirms a particularly high mutation rate in the iconic cancer IncRNA, NEAT1, whose functional significance has been debated in previous studies. We apply in cellulo mutagenesis to identify discrete regions of NEAT1 where SNVs reproducibly increase cell proliferation in both cancerous and normal backgrounds. We show that mutations in the 5' region of NEAT1 alter ribonucleoprotein assembly and boost the population of subnuclear paraspeckles, thus linking genetic mutations to cellular fitness. In summary, this work establishes function-altering somatic mutations in vulnerable IncRNA sites as a route by which cells acquire fitness during tumorigenesis. Such mutations may act by altering the composition of IncRNA-containing ribonucleoproteins. 


\section{Introduction}

Tumours arise and develop via somatic mutations that confer a fitness advantage on cells (Campbell et al., 2020). Such "driver" mutations exert their phenotypic effect by altering the function of genes or genomic elements, and may be identified by signatures of positive evolutionary selection (Rheinbay et al., 2020). Identifying driver mutations, and the "driver genes" through which they act, is a critical step towards understanding and treating cancer (Campbell et al., 2020; Rubio-Perez et al., 2015).

Most tumours are characterised by a limited and recurrent sequence of driver mutations, which are shared by cells within and between tumours (Nowell, 1976; Tomasetti et al., 2015). Evidence from modelling and genetically-modified mouse models (Collins et al., 2012) has cemented the view that such "gatekeeper" mutations are necessary and rate-limiting events for tumorigenesis (Vogelstein and Kinzler, 2015). With the exception of the TERT promoter (Vinagre et al., 2013), these almost invariably affect protein-coding sequences (Sondka et al., 2018).

However, the vast majority of single nucleotide variants (SNVs) fall outside proteincoding genes (Khurana et al., 2016). Combined with increasing awareness of the disease roles of noncoding genomic elements (Gloss and Dinger, 2018), this naturally raises the question of whether non-protein coding mutations also contribute to cancer cell fitness (Elliott and Larsson, 2021). Growing numbers of both theoretical (Corona et al., 2020; Hornshøj et al., 2018; Kim et al., 2016; Melton et al., 2015; Puente et al., 2015; Umer et al., 2021) and experimental studies (Cho et al., 2018; Li et al., 2020; Rheinbay et al., 2020; Zhou et al., 2020; Zhu et al., 2020) implicate noncoding SNVs in cell fitness by altering the function of elements such as enhancers, promoters, insulator elements and small RNAs (Shuai et al., 2019). Given the relative robustness of noncoding elements to sequence changes, in contrast to protein-coding open reading frames (ORFs), it is anticipated that noncoding drivers exert weaker phenotypic effects (Elliott and Larsson, 2021). These may help explain the existence of widespread "minidrivers" predicted by recent modelling (Castro-Giner et al., 2015; Kumar et al., 2020). 
Surprisingly, one important class of cancer-promoting noncoding genes has been largely overlooked to date: long noncoding RNAs (IncRNAs) (Statello et al., 2021). LncRNA transcripts are modular assemblages of functional elements that can interact with other nucleic acids and proteins via defined sequence or structural elements (Ghandi et al., 2018; Statello et al., 2021). Of the $>50,000$ loci mapped in the human genome (Uszczynska-Ratajczak et al., 2018), hundreds of "cancer-IncRNAs" have been demonstrated to act as oncogenes / tumour suppressors (Vancura et al., 2021). Their functional importance is further supported by copy number variants (CNVs) (Akrami et al., 2013; Hu et al., 2014; Leucci et al., 2016), tumourinitiating transposon screens in mouse (Carlevaro-Fita et al., 2020) and function-altering germline cancer variants (Redis et al., 2016).

We and others have previously reported statistical evidence for mutation-enriched candidate driver IncRNAs (Lanzós et al., 2017a; Mularoni et al., 2016; Rheinbay et al., 2020). For example, NEAT1 has been reported for its high mutation rate across a variety of cancers (Fujimoto et al., 2016; Lanzós et al., 2017a; Rheinbay et al., 2017). This raises the possibility that a subset of cancer-IncRNAs may also act as "driver-IncRNAs", where SNVs promote cell fitness by altering IncRNA activity. Nonetheless, it has been argued that mutations in NEAT1 and other IncRNAs represent phenotypically-neutral passengers (Lanzós et al., 2017a; Rheinbay et al., 2020), and no fitness-altering somatic IncRNA SNVs have been experimentally validated to date.

In the present study, we investigate the existence of driver-IncRNAs. We develop an enhanced IncRNA driver discovery tool, and use it comprehensively map candidate driverIncRNAs across the largest cohort to date of somatic SNVs from both primary and metastatic tumours. We evaluate the clinical and genomic properties of these candidates. Finally, we employ a range of functional and mechanistic assays to gather the first experimental evidence for fitness-altering driver mutations acting through IncRNAs. 


\section{Results}

\section{Integrative driver IncRNA discovery with ExInAtor2}

Driver genes can be identified by signals of positive selection acting on their somatic mutations. The two principal signals are mutational burden (MB), an elevated mutation rate, and functional impact $(\mathrm{FI})$, the degree to which mutations are predicted to alter encoded function. Both signals must be compared to an appropriate background, representing mutations under neutral selection.

To search for IncRNAs with evidence of driver activity, we developed ExInAtor2, a driverdiscovery pipeline with enhanced sensitivity due to two key innovations: integration of both MB and FI signals, and empirical background estimation (see Methods) (Figure 1A, Supplementary Figure $1 \mathrm{~A}, \mathrm{~B})$. For $\mathrm{MB}$, local background rates are estimated, controlling for covariates of mutational signatures and large-scale effects such as replication timing, which otherwise can confound driver gene discovery (Lawrence et al., 2013). For FI, we adopted functionality scores from the Combined Annotation Dependent Depletion (CADD) system, due to its widespread use and compatibility with a range of gene biotypes (Rentzsch et al., 2021). Importantly, ExInAtor2 remains agnostic to the biotype of genes / functional elements, allowing independent benchmarking with established protein-coding gene data.

\section{Accurate discovery of known and novel driver genes}

We began by benchmarking ExInAtor2 using the maps of somatic single nucleotide variants (SNVs) from tumour genomes sequenced by the recent PanCancer Analysis of Whole Genomes (PCAWG) project (Campbell et al., 2020), comprising altogether 45,704,055 SNVs from 2,583 donors (Figure 1B, Methods). As it was generated from whole-genome sequencing (WGS), this dataset makes it possible to search for driver genes amongst both non-proteincoding genes (including IncRNAs) and better-characterised protein-coding genes.

To maximise sensitivity and specificity, we prepared a carefully-filtered annotation of IncRNAs. Beginning with high-quality curations from Gencode (Frankish et al., 2019), we isolated intergenic IncRNAs without evidence for possible protein-coding capacity. To the resulting set of 6981 genes (Figure 1C), we added the set of confident, literature-curated IncRNAs from Cancer LncRNA Census 2 dataset (Vancura et al., 2021), for a total set of 7275 genes. 
We compared the performance of ExInAtor2 to ten leading driver discovery methods and PCAWG's consensus measure, which integrates all ten and has better performance than any individual method (Figure 2A) (Rheinbay et al., 2017). Performance was benchmarked on curated sets of protein-coding and IncRNA cancer genes (Figure 2B). Judged by correct identification of cancer IncRNAs at a false discovery rate (FDR) cutoff of $<0.1$, ExInAtor2 displayed the best overall accuracy in terms of $F_{1}$ measure (Figure 2C, D). ExInAtor2 displayed good statistical behaviour, since quantile-quantile (QQ) analysis of resulting $p$-values $(P)$ displayed no obvious inflation or deflation and has amongst the lowest Mean Log Fold Change (MLFC) values (Figure 2E), together supporting its low and controlled FDR.

ExInAtor2 is biotype-agnostic, and protein-coding driver datasets are highly refined (Figure 2B). To further examine its performance, we evaluated sensitivity for known proteincoding drivers from the benchmark Cancer Gene Census (Sondka et al., 2018). Again, ExInAtor2 displayed competitive performance, characterised by low false positive predictions (Supplementary Figure 2A-C).

To test ExInAtor2's FDR estimation, we repeated the IncRNA analysis on a set of carefully-randomised pancancer SNVs (see Methods). Reassuringly, no hits were discovered and QQ plots displayed neutral behaviour (MLFC 0.08) (Supplementary Figure 2D). Similar results were obtained with SNVs from an independent randomisation method (data not shown). Analysing at the level of individual cohorts, ExInAtor2 predicted 3 / 40 IncRNA-cohort associations in the simulated / real datasets, respectively. This corresponds to an empirical FDR rate of 0.075 , consistent with the nominal FDR cutoff of 0.1 .

We conclude that ExInAtor2 identifies known driver genes with a low and controlled false discovery rate.

\section{The landscape of driver IncRNA in primary human tumours}

We next set out to create a genome-wide panorama of mutated IncRNAs across human primary cancers. Tumours from PCAWG were grouped into a total of 37 cohorts, ranging in size from two tumours (Cervix-AdenoCa, Lymph-NOS and Myeloid-MDS tumour types) to 314 (Liver-HCC tumour type), in addition to the entire pancancer set (Figure 3A). 
After removing likely false positive associations using the same stringent criteria as PCAWG (Campbell et al., 2020), ExInAtor2 revealed altogether 21 unique cancer-IncRNA associations, involving 17 IncRNAs (Figure 3B) - henceforth considered putative "driver IncRNAs". Of these, nine are annotated IncRNAs that have not previously been linked to cancer, denoted "novel". The remaining "known" candidates are identified in the literaturecurated Cancer LncRNA Census 2 dataset (Vancura et al., 2021). Known IncRNAs tend to be hits in more individual cohorts than novel IncRNAs, with cases like NEAT1 being detected in four cohorts (Figure 3B). While most driver IncRNAs display exonic mutation rates $~ 50$-fold greater than background (coloured cells, Figure 3B), the number of mutations in such genes is diverse between cohorts, being Pancancer, Lymph-CLL and Skin-Melanoma the biggest contributors of mutations.

Supporting the accuracy of these predictions, the set of driver IncRNAs is highly enriched for known cancer IncRNAs (Vancura et al., 2021) (8/17 or 48\%, Fisher test $\mathrm{P}=2 \mathrm{e}-6)$ (Figure $3 C)$. Driver IncRNAs are also significantly enriched in three other independent literaturecurated databases (Supplementary Figure 3A).

\section{Driver IncRNAs carry features of functionality and clinical relevance}

To further evaluate the quality of driver IncRNA predictions, we tested their association with genomic and clinical features expected of bona fide cancer genes. LncRNA catalogues are likely to contain a mixture of both functional and non-functional genes. The former group is characterised by purifying evolutionary selection and high expression in healthy and diseased tissues (Carlevaro-Fita et al., 2020). We found that driver IncRNAs display higher evolutionary sequence conservation and higher steady-state levels in healthy organs (Figure 3D). Their sequence also contains more microRNA binding sites, suggesting integration with post-transcriptional regulatory networks.

In contrast, we could find no evidence that driver IncRNAs are enriched for genomic covariates and features arising from artefactual results. They have earlier replication timing (whereas later replication is associated with greater mutation) (Stamatoyannopoulos et al., 2009), less exonic repetitive sequence (ruling out mappability biases), and similar exonic GC content (ruling out sequencing bias) compared to tested non-candidates (Figure 3D). However, driver IncRNAs tend to have longer spliced length, likely reflecting greater statistical power for longer genes that affects all driver methods (Lanzós et al., 2017a). 
Driver IncRNAs also have clinical features of cancer genes (Figure 3E). They are on average 158-fold higher expressed in tumours compared to normal tissues (133 vs 0.84 FPKM) (Figure 3E, PCAWG RPKM), 2.15-fold enriched for germline cancer-associated small nucleotide polymorphism (SNP) in their gene body (4.7\% vs $2.5 \%$ ) (Figure 3E, SNPs per MB), and enriched in orthologues of driver IncRNAs discovered by transposon insertional mutagenesis (TIM) screens in mouse (17.6 vs 1.6\%) (Supplementary Figure 3A) (Vancura et al., 2021). Finally, driver IncRNAs significantly overlap growth-promoting hits discovered by CRISPR functional screens (11.8 vs 1.3\%) (Supplementary Figure $3 \mathrm{~A}$ ). In conclusion, driver IncRNA display evidence for functionality across a wide range of functional and clinical features, strongly suggesting that they are enriched for bona fide cancer driver genes.

\section{The landscape of IncRNA drivers in metastatic tumours}

We further extended the driver IncRNA landscape to metastatic tumours, using 3,527 genomes from 31 cohorts sequenced by the Hartwig Medical Foundation (Supplementary Figure 3A,C,D) (Priestley et al., 2019). Performing a similar analysis as above, we identified 43 driver IncRNAs in a total of 53 IncRNA-tumour combinations (Supplementary Figure 3B). Eight predicted drivers are known cancer IncRNAs, significantly higher than random expectation ( $P=0.004)$ (Figure $3 C$ ). Further adding confidence to these findings is the significant overlap of driver IncRNAs identified in the metastatic and primary tumour cohorts (Figure 3C).

\section{Mutations in novel driver IncRNAs promote cell fitness}

A number of uncharacterised IncRNAs were implicated in the above analyses. We next tested whether they do indeed play any role in cell phenotypes of relevance to cancer. AC078785.2, herein named MILC (Mutated in Liver Cancer) displayed elevated mutation rates in Hepatocellular Carcinoma (HCC) tumours (Figure 4A) and has been detected as driver in both the PCWG and HFM datasets. It has, to our knowledge, never previously been implicated in cancer. According to the latest Gencode version 38, its single annotated isoform comprises three exons, and displays low expression in normal tissues (Supplementary Figure 4A). We could detect MILC in two HCC cell lines, HuH7 and SNU-475 (Figure 4C and Supplementary Figure 4C). To perturb MILC expression, we designed two different antisense oligonucleotides (ASOs) that reduced steady-state levels by $>50 \%$ in both cell lines (Figure 4B,C and Supplementary Figure $4 \mathrm{C}$ ). We evaluated the role of MILC in HCC cell proliferation, by measuring changes in growth rates following ASO transfection. The significant decrease in growth resulting from both ASOs in both cell backgrounds points to the importance of MILC in cell fitness (Figure 4D and Supplementary Figure 4D). 
These results prompted us to ask whether MILC can also promote cell growth in other cancer types. Thus, we turned to CRISPR-activation, to upregulate the IncRNA from its endogenous locus in HeLa cervical carcinoma cells. Three independent sgRNAs increased gene expression by 4 to $\sim 20$-fold (Figure 4E and Supplementary Figure 4B), of which two significantly and specifically increased cell proliferation (Figure $4 \mathrm{~F}$ ).

Having established that MILC promotes cell growth, we next asked whether tumour mutations can enhance this activity, as would be expected for driver mutations. To do so, we designed overexpression plasmids for the wild-type or mutated forms of the transcript (Figure $4 G)$. The mutated form contained four SNVs, some of them recurrently observed in independent tumours from both PCAWG and HFM dataset (Figure 4A). Transfection of wildtype MILC boosted cell growth, consistent with ASO results above. More important, the mutated form resulted in a significant additional increase cell proliferation, compared to the wild-type (Figure 4H).

Another IncRNA, AC087463.1, herein named MIHNC (Mutated in Head and Neck Cancer) was identified as a potential driver in the Head and Neck (HN) tumour cohort (Figure 4I). MIHNC is transcribed from the same locus as the IncRNA PWRN1, previously reported as a tumour suppressor in gastric cancer (Chen et al., 2018). It is annotated as a single isoform with three exons (Figure 4I), with the mutations falling in the second, unique exon (Figure 4I). A similar strategy as above showed that overexpression of a mutated form carrying 5 SNVs (Figure $4 \mathrm{~K}$ ) increased tumorigenicity in $\mathrm{HN}$ cells, as measured by colony-forming potential (Figure 4J).

Together, these results show that newly-discovered IncRNAs with positively-selected SNVs are capable of promoting fitness in tumour cell backgrounds and, critically, this activity is enhanced by tumour mutations.

\section{Mutations in NEAT1 promote cell fitness and correlate with survival}

To gain mechanistic insights into how fitness-enhancing driver mutations may act through IncRNAs, we turned to a relatively well-understood IncRNA, NEAT1, for which confident mechanistic and functional data is available. Based on ExInAtor2 analysis, NEAT1 mutations, spanning the entire gene length, display evidence for positive selection in altogether 4 and 3 cancer cohorts in PCAWG and Hartwig, respectively. PCAWG and others also noted this highly elevated mutation rate in the NEAT1 gene, although it has been argued that these result from neutral passenger processes, possibly linked to the high expression of the gene (Fujimoto et al., 2016; Rheinbay et al., 2020; Wedge et al., 2018). 
NEAT1 produces short and long isoforms (called NEAT1_1 / NEAT1_2) of 3.7 and 22.7 kb, respectively (Sasaki et al., 2009), which are completely overlapping at the 5' of the gene (Figure 5B). NEAT1_1 is a ubiquitous, abundant, polyadenylated and highly conserved transcript (Nakagawa et al., 2011). In contrast, NEAT1_2, responsible for formation of membraneless nuclear paraspeckle structures, is not polyadenylated and expressed under specific conditions or in response to various forms of stress (Adriaens et al., 2019; McCluggage and Fox, 2021).

We sought to test whether indels in NEAT1 can act as drivers. We hypothesised that tumour indels could be simulated wild-type Cas9 protein, which is known to cause similar mutations when double strand breaks are resolved by error-prone DNA repair pathways (Cho et al., 2018; Liu et al., 2019). We selected six regions of NEAT1, based on high mutation density, evolutionary conservation and known functions (Yamazaki et al., 2018), hereafter called Reg1, Reg2, etc.., and targeted them with altogether 15 sgRNAs (Figure 5A). To control for the non-specific fitness effects of double strand breaks (DSBs) (Aguirre et al., 2016; Haapaniemi et al., 2018), we also created two neutral control sgRNAs targeting AAVS1 locus, and a positive-control paired sgRNA (pgRNA) to delete the entire NEAT1_1 region (Figure 5B and Supplementary Figure 5B). Sequencing of treated cells' gDNA revealed narrowly-focussed substitutions and indels at target regions, similar to that observed in real tumours (Figure 5C and Supplementary Figure 5A).

To quantify mutations' effects on cell fitness, we established a competition assay between mutated mCherry-labelled cells and control GFP-labelled cells (Figure 5D) (Cho et al., 2018). As expected, deletion of entire NEAT1_1 in HeLa cells led to reduced growth (KO), while control sgRNAs did not (Figure 5D). Notably, HeLa cells carrying NEAT1 mutations in defined regions displayed increased fitness: two at the 5' of the gene (Reg2 and Reg3), one internally near the alternative polyadenylation site (Reg4) and one at the 3' end (Reg5) (blue line, Figure 5D). These findings were supported in 3/4 cases in HCT116 colorectal carcinoma cells (green line, Figure 5D).

To corroborate these findings, we repeated fitness assays in the more complex pooled competition assay. Here, the evolution of defined mixtures of mutant cells is quantified by amplicon sequencing of sgRNA barcodes. Consistent with previous results, cells carrying NEAT1 mutations outcompeted control cells over time (Figure 5E).

These results were obtained from monolayer cells, whose relevance to real tumours is disputed. Thus, we performed additional experiments in 3-dimensional spheroids grown from mutated HCT116 cells, and observed again that Reg2 mutations led to increased growth (Figure 5F). 
The experiments thus far were performed in transformed cancer cells. To investigate whether NEAT1 mutations also enhance fitness in a non-transformed background, we performed similar experiments in MRC5 immortalised foetal lung fibroblasts. Again, NEAT1 mutations were observed to increase fitness, in terms of cell growth (Figure $5 \mathrm{G}$ ) and, at least for Reg2, in terms of anchorage-independent growth (Figure $5 \mathrm{H}$ ).

We sought independent evidence for the importance of NEAT1 mutations in real-life cancer progression. Using patient survival data from the PCAWG cohort, we asked whether presence of a NEAT1 mutation correlates with shorter survival. Indeed, in lymphoid cancer patients, NEAT1 mutations correlate with significantly worse prognosis (Figure 5l). This effect remains even after accounting for differences in total mutation rates using the Cox proportional hazards model $(P=0.02)$.

In summary, NEAT1 tumour mutations consistently increase cell fitness in vitro independent of genetic background, and are associated with poor prognosis in lymphoid cancer patients.

\section{Mutations alter the NEAT1 protein interactome and increase paraspeckle formation}

NEAT1 is a necessary component of subnuclear paraspeckles (Fox et al., 2002; Hutchinson et al., 2007; McCluggage and Fox, 2021), which assemble when specific architectural proteins bind to nascent NEAT1_2 transcripts (Mao et al., 2011). Paraspeckles are nuclear condensates containing diverse gene regulatory proteins (McCluggage and Fox, 2021). They are often observed in cancer cells, (Adriaens et al., 2016), and are associated with poor prognosis ( $\mathrm{Li}$ et al., 2018a). Thus, we hypothesised that NEAT1 mutations might affect cell fitness via alterations in paraspeckle number or structure.

We first evaluated changes in NEAT1 expression and isoform usage in response to mutations. Mutations caused no statistically-significant change in NEAT1_1 expression, while deletion of NEAT1_1 reduced steady-state levels, as expected (Figure 6A). Interestingly, the only mutation to significantly increase NEAT1_2 levels was in Region 4 (Figure 6B), which is consistent with the fact that it contains the alternative polyadenylation site that mediates switching between the short and long isoforms (Naveed et al., 2021).

Using fluorescence in situ hybridisation (FISH) with NEAT1_2 probes, we next asked whether mutations impact on paraspeckle number or structure (Figure 6C). Despite changes in isoform expression noted above, mutations in Region 4 resulted in no change in the number or size of paraspeckles, in line with previous findings (Yamazaki et al., 2018) (Figure 6D,E). However, mutations in Region 2 yielded a significant increase in number and size of paraspeckles (Figure 6C-E). 
NEAT1 is known to function via a diverse cast of protein partners. Region 2 mutations overlap several known protein binding sites, and fall in or near to areas of deep evolutionary conservation of sequence and structure (Supplementary Figure $5 \mathrm{C}$ ).

To better understand how Region 2 mutations alter NEAT1 function, and evaluate if mutation could affect the binding of proteins to NEAT1 (Figure 6F), we compared the proteininteractome of wild-type and mutant RNA by in vitro pulldown coupled to mass-spectrometry. We created a $288 \mathrm{nt}$ fragment of NEAT1-Region 2 for wild-type (WT) and mutated sequence, the latter containing two SNVs observed in patient tumours (Figure 6G). We performed RNA pull-down with nuclear lysate from HeLa cells, followed by mass spectrometry. Altogether, 154 interacting nuclear proteins were identified for wild-type sequence. Supporting the usefulness of this approach, interacting proteins highly enriched for both known NEAT1-binders and paraspeckle proteins (see Methods) and include well known examples like NONO (Simko et al., 2020; Yamazaki et al., 2018) (Figure 6H). Comparing mutant to WT interactomes, we observed widespread changes in NEAT1 complexes: altogether $8(4.6 \%)$ proteins are lost by mutant RNA, and 18 (10.3\%) gained (Figure 6I).

We investigated whether mutations create or destroy known binding motifs of changing proteins, but could find no evidence for this. However, we did note that mutations lead to increased binding of previously-discovered interactors, U2SURP and PTBP1 (Figure 6I). Intriguingly, increased binding was also observed for PQBP1 protein, whose disordered domain has been linked to condensate formation, offering a potential mechanism in facilitating paraspeckle formation (Kunde et al., 2011). Conversely, STRING analysis revealed that the proteins lost upon mutation are highly enriched for members of the core RNA Polymerase II complex (strength=2.51, $\mathrm{P}=0.016$; basic list enrichment by STRING, Benjamini-Hochberg corrected) and physically interacting with other proteins of this complex (Figure 6J). In summary, tumour mutations in NEAT1 give rise to reconfiguration of the protein interactome, creating several potential mechanisms by which paraspeckles formation is promoted in transformed cells. 


\section{Discussion}

Understanding which mutations give rise to pathogenic cell fitness, and how they do so, are fundamental goals of cancer genomics. Here we have focussed on a particularly intriguing class of potential driver elements, the IncRNAs, which are known to be both highly mutated and essential for cancer cell hallmarks, and yet for which no driver has been experimentally validated to date (Fujimoto et al., 2016; Lanzós et al., 2017a; Nik-Zainal et al., 2016; Rheinbay et al., 2020).

To address this gap, we here developed an improved method, ExInAtor2, to search for driver IncRNAs based on integrated signatures of positive selection. In total, this identified 54 candidate driver IncRNAs across the largest tumour cohort tested to date. The value of these predictions is supported by consistency between independent cohorts, overlap with various cancer IncRNA databases, and from functional screens in mouse. Nevertheless, this approach suffers from a variety of constraints, from false positives arising from localised, non-selected mutational processes, to false negatives due to the limited sample size. Such factors have limited the confidence with which previous studies (Lanzós et al., 2017a; Mularoni et al., 2016) could interpret highly mutated IncRNAs to be genuine "driver genes", underlining the significance of experimental validation performed here.

ExInAtor2 identified two novel IncRNAs, MIHNC (Head and Neck cancer) and MILC (Hepatocellular Carcinoma), which follow-up experiments demonstrated (1) to promote cancer cell growth in their wild-type form, and (2) crucially, that this activity is further enhanced by tumour mutations. These findings provide experimental support for driver analysis applied to IncRNAs, and of the ability of IncRNA SNVs to alter cell fitness. 
Among the candidate driver IncRNAs we identified the widely-studied NEAT1. Previous tumour sequencing studies have noted the elevated density of SNVs at this locus, but generally attributed them to passenger mutational processes, possibly a consequence of unusually high transcription rate (Fujimoto et al., 2016; Lanzós et al., 2017a; Nik-Zainal et al., 2016; Rheinbay et al., 2020). Here, we have provided experimental evidence, via naturalistic in cellulo mutagenesis with CRISPR-Cas9, that NEAT1 SNVs reproducibly give rise to increased cell proliferation, in a range of backgrounds including non-transformed cells. The latter raises the intriguing possibility that NEAT1 SNVs might contribute at relatively early phases in tumorigenesis. Other observations are worthy of mention. Firstly, amongst fitness-altering NEAT1 SNVs, we only observed those that increase growth, and none that decreased it. Secondly, not all tested regions of NEAT1 could host fitness-altering mutations, and these were clustered at previously-mapped functional elements in mature RNA (Adriaens et al., 2019; Yamazaki et al., 2018). Altogether, these findings suggest that tumour SNVs at particular regions of NEAT1 are phenotypically non-neutral and capable of increasing cell fitness. The notion that the NEAT1 gene represents a vulnerability to tumorigenesis is further supported by independent transposon insertional mutagenesis screens in mouse (Carlevaro-Fita et al., 2020).

The relatively well-understood role of NEAT1 in assembling ribonucleoprotein phaseseparated paraspeckle organelles afforded important insights into SNVs' molecular mechanisms. Introduction of tumour mutations at the gene's 5' end impacted protein binding, including a significant loss of interaction with the RNA Polymerase II complex mediated by known NEAT1 interactor TAF15. Other known protein interactions are potentiated in mutated RNA, suggesting that changes in paraspeckles may be mediated by both gains and losses of protein interactions. The fact that these same mutations gave rise to increased numbers and sizes of paraspeckle structures, suggest a model where SNVs alter the assembly of NEAT1 ribonucleoprotein complexes, thereby promoting paraspeckle formation and hence cell growth.

Future studies will have to address a number of gaps and questions raised here. Firstly, the available of larger tumour cohorts will afford statistical power to discover candidate driver IncRNAs with greater accuracy, while improved statistical models and gene annotations will reduce false positives and false negatives, respectively. While we have provided functional experimental evidence for effects on cell phenotype arising from SNVs, it will be important to replicate this in better models, notably by introducing precise tumour mutations into cellular genomes (eg by recent Prime Editing method (Anzalone et al., 2020) and testing their effects in faithful tumour models, such as mice or tumour organoids (Artegiani et al., 2020; Miura et al., 2017). Finally, key mechanistic questions remain to be answered, such as the precise protein partners whose interaction is altered to result in paraspeckle changes. 
The future discovery and validation of numerous phenotype-altering IncRNA mutations could have important implications for therapy. Patients with tumours carrying identified driver SNVs in tumour-specific IncRNAs might be treated using cocktails of antisense oligonucleotides targeting that panel of IncRNAs, for personalised, low-toxicity and effective therapy (Agrawal, 2020; MacLeod and Crooke, 2017; Wang et al., 2020).

In summary, this work represents the first experimental evidence that fitness-boosting somatic tumour mutations can act via changes to IncRNA function. We have sketched a first mechanistic outline of how this process occurs via altered protein interaction and changes to membraneless organelles, in this case, paraspeckles. Our catalogue of candidate driver IncRNAs across thousands of primary and metastatic tumours provides a foundation for future elucidation of the extent and mechanism of driver IncRNAs. 


\section{Acknowledgements}

The results shown here are based upon data generated by the TCGA, PCAWG and GTEx consortia. We thank Iñigo Martincorena (Sanger Institute) for generously providing certain data analysis scripts. We thank Federico Abascal (Sanger Institute) for generously providing cancer cell fraction data. We thank Adrian Ochsenbein, Carsten Riether, Simon Haefliger, Thomas Marti, Renwang Peng, (Inselspital University Hospital of Bern) for many insightful conversations. We thank Basak Ginsbourger (DBMR) for administrative support, and Willy Hofstetter and Patrick Furer (DBMR) for logistical support. All computation was performed on the Bern Interfaculty Bioinformatics Unit computing cluster maintained by Rémy Bruggmann and Pierre Berthier. This publication and the underlying study have been made possible partly on the basis of the data that Hartwig Medical Foundation has made available. Work in the Johnson laboratory is funded by the Medical Faculty of the University of Bern, the University Hospital of Bern, the Helmut Horten Stiftung, Swiss Cancer Research Foundation (4534-082018), Science Foundation Ireland through Future Research Leaders award 18/FRL/6194, and the Swiss National Science Foundation through the National Centre of Competence in Research (NCCR) "RNA \& Disease". 


\section{Methods}

\section{ExInAtor2 algorithm}

ExInAtor2 is composed of two separate modules for detection of positive selection: one for recurrence $(\mathrm{RE})$, comparing the exonic mutation rate to that of the local background; another for functional impact $(\mathrm{FI})$, comparing the estimated functional impact of mutations to background, both estimated in exons.

As an improvement to the first version of ExInAtor (Lanzós et al., 2017), the RE module compares the number of observed exonic mutations against a distribution of simulated exonic counts (Supplementary Figure 1A), obtained by random repositioning of the variants the between the exonic and background regions while maintaining the same trinucleotide spectrum. Background region is defined for each gene as introns plus $10 \mathrm{~kb}$ up and downstream, after removing nucleotides overlapping exons from any other gene. Exonic and background regions can be further filtered to remove any additional "masked" regions defined by the user. In this manuscript, this functionality was used to mask with low mappability obtained from the UCSC Genome Browser (Supplementary Files).

The use of local background and controlling for trinucleotide content is intended to avoid known sources of false positives arising from covariates in mutational processes and mutational signatures, such as replication timing, gene expression, chromatin state, etc (Lawrence et al., 2013).

A $p$-value is assigned to each gene, being the fraction of simulations with higher or equal number of mutations compared to the observed number (Formula 6 ).

$$
R E_{p-\text { value }}=\frac{\# \text { of simulated exonic counts } \geq \text { observed exonic count }}{\text { total } \# \text { of simulations }}
$$

\section{Formula 6: $p$-value calculation for the recurrence (RE) module.}

The second FI module compares the mean functional score of the observed exonic mutations to a distribution of simulated values. Simulations are performed by random repositioning of mutations in exonic regions, while maintaining identical trinucleotide content (Supplementary Figure 1B). Similar to the RE model, a $p$-value is obtained by comparing the number of simulations with an exonic mean functional score higher or equal to the observed value (Formula 7). This module work with any base-level scoring method. Given its previous successful use and integrative nature, we selected the Combined Annotation Dependent Depletion (CADD) scoring system (Rentzsch et al., 2021; Rentzsch et al., 2019). 


$$
F I_{p-\text { value }}=\frac{\# \text { of simulated exonic means } \geq \text { observed exonic mean }}{\text { total \# of simulations }}
$$

Formula 7: $p$-value calculation for the Functional Impact (FI) module.

In a final step, RE and FI p-values are combined using the Fisher method (Formula 8).

$$
\text { Combined }_{p-\text { value }}=-2 *\left[\ln \ln \left(R E_{p-\text { value }}\right)+\ln \ln \left(F I_{p-\text { value }}\right)\right]
$$

Formula 8: Fisher method for $p$-value integration.

\section{Tumour somatic mutations}

The principal source of mutations were primary tumours from the Pan-Cancer Analysis of Whole Genomes (PCAWG) project (Campbell et al., 2020). This dataset was created according to a uniform and strict methodology, including collection of samples, DNA sequencing and somatic variant calling, aggressive filtering to remove potential artefacts and false positive mutations (Campbell et al., 2020). For practical reasons, we only considered Single Nucleotide Variants (SNVs) arising from substitutions, insertions and deletions of length $1 \mathrm{bp}$ (indels) (Figure 1B). After this filtering, the PCAWG dataset comprises 37 cancer cohorts, 2,583 samples and 45,703,485 SNVs (Figure 1B). Analyses were performed either on individual cohorts, or on the "Pancancer" union of all cohorts.

\section{Gene annotation and filtering}

We employed a filtered IncRNA gene annotation based upon Gencode annotation. Beginning with Gencode v19 annotation, we discarded IncRNA genes overlapping proteincoding genes, or containing at least one transcript predicted to be protein-coding by CPAT (Wang et al., 2013), with default settings of coding potential $>=0.364$. To the remaining list of 6981 genews, we added 294 genes from Cancer LncRNA Census (CLC) (Vancura et al., 2021), not annotated in Gencode v19. The resulting set of 7275 IncRNA genes were used here unless otherwise specified (Figure 1C).

\section{ExInAtor2 benchmarking against other driver discovery methods}


We collected driver predictions from 10 methods, in addition to the combined predictions generated by the PCAWG driver group (PCAWG combined, PCAWGC) that displayed best overall performance (Rheinbay et al., 2020). We only selected PCAWG methods that were run in both protein-coding and IncRNAs, and for which predictions were available for individual cohorts (Figure $2 \mathrm{~A}$ ).

The original PCAWG publication used carefully filtered annotations for protein-coding and IncRNA genes (Rheinbay et al., 2020). Only coding sequences (CDS) of protein-coding genes were considered, while IncRNAs were strictly filtered by distance to protein coding genes, transcript biotype, gene length, evolutionary conservation and RNA expression. For benchmarking, we ran ExInAtor2 using the same PCAWG annotations.

\section{Evaluation of $p$-value distributions}

Under the assumption that most genes are not cancer drivers and follow the null distribution, the collection of $p$-values should mimic a uniform distribution with deviation of a small number of genes at very low p-values (Tokheim et al., 2016). Quantile-quantile plots (QQ-plot) (Figure 2B and Supplementary Figure 3A) display the observed and expected $p$ values in - $\log 10$ scale. In order to generate the theoretical distribution for each driver method across all 37 cohorts and the Pancancer set, we ranked the total list of $n$ observed $p$-values from lowest to highest, then for each $i$ observed $p$-value we calculated an expected $p$-value according to the uniform distribution (Formula 1).

$$
\text { expected }_{i}=\frac{i}{n}
$$

Formula 1: Expected $p$-value calculation. $i$ represents the rank of the corresponding observed $p$-value in the total distribution of $n$ observed $p$-values, therefore $i$ values range from 1 to $n$.

For each driver method, only genes with a reported $p$-value were included in this analysis, i.e., NA cases were discarded. By visual inspection of the $Q Q$-plots, a correct observed distribution of $p$-values should follow a line with 0 as intercept and 1 as slope, where extreme values beyond approximately 2 in the $x$-axis should deviate above the diagonal line. We used the Mean Log Fold Change (MLFC) (Formula 2) to numerically estimate such deviation and evaluate the performance of driver gene predictions (Tokheim et al., 2016). The closer to zero the MLFC, the better the statistical modelling of passenger genes following the null distribution (Tokheim et al., 2016). 


$$
M L F C=\frac{1}{n} * \sum_{i}^{n}\left|\left(\frac{\text { observed }_{i}}{\text { expected }_{i}}\right)\right|
$$

Formula 2: Mean Log Fold Change (MLFC). $n$ represents the total number of $p$-values an $i$ the lowest $p$-value.

\section{Gene benchmark sets}

We downloaded known driver genes from the Cancer Gene Census (Sondka et al., 2018) (CGC) (www.cancer.sanger.ac.uk/census) on 06/02/2019 as a TSV file. We extracted all Gencode ENSG identifiers, resulting in a list of 703 genes. For IncRNAs we used the second version of the Cancer LncRNA Census (Vancura et al., 2021), which contains 513 Gencode IncRNAs.

\section{Precision, sensitivity and F1 comparison}

CGC and CLC genes were used as ground truth for driver predictions of protein-coding and IncRNAs, respectively. Three metrics were used to compare driver predictions: Precision, the proportion of predictions that are ground truth genes (Formula 3); Sensitivity, the fraction of ground truth genes that are correctly predicted (Formula 4); F1-score, the harmonic mean of precision and sensitivity (Formula 5).

$$
\text { Precision }=\frac{T P}{T P+F P} * 100
$$

Formula 3: Precision.

$$
\text { Sensitivity }=\frac{T P}{T P+F N} * 100
$$

Formula 4: Sensitivity.

$$
F 1-\text { score }=2 * \frac{\text { Precision } * \text { Sensitivity }}{\text { Precision }+ \text { Sensitivity }}
$$

Formula 5: F1-score. 


\section{Simulated mutation datasets}

To generate realistic simulated data, each mutation was randomly repositioned to another position with identical trinucleotide signature (ATA > ATA, being the central nucleotide the one mutated) within a window of $50 \mathrm{~kb}$ on the same chromosome.

\section{Generation and comparison of genomic features}

Evolutionary conservation: We downloaded base-level PhastCons scores for all 46way and 100way alignments (Siepel et al., 2005) from the UCSC Genome Browser (Haeussler et al., 2019). We calculated the average value across all exons of each gene.

Expression in normal samples: We obtained RNA-seq expression estimates in transcripts per million (TPM) units for 53 tissues from GTEx (https://gtexportal.org/home/datasets). For tissue specificity, we calculated tau values as previously described (Yanai al., 2005) (https://github.com/severinEvo/gene expression/blob/master/tau.R).

Replication timing: We collected replication time data of 16 different cell lines from the UCSC browser (Haeussler et al., 2019) (http://genome.ucsc.edu/cgi-

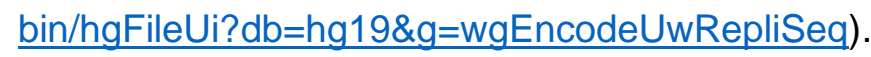

miRNA binding: We downloaded both bioinformatically predicted (miTG scores) and experimentally validated miRNA binding to IncRNAs from LncBase (Paraskevopoulou et al., 2015)

(http://carolina.imis.athenainnovation.gr/diana tools/web/index.php?r=Incbasev2\%2Findex).

Tumour expression: Expression values in units of FPKM-uq (referred as PCAWG RPKM in Figure 4D) were obtained from PCAWG (Campbell et al., 2020).

Drug-expression association: We extracted expression-drug association $p$-values from LncMAP (Li et al., 2018b) (http://bio-bigdata.hrbmu.edu.cn/LncMAP).

Germline cancer small nucleotide polymorphisms (SNPs): We downloaded SNPs from the GWAS Catalogue (Buniello et al., 2019) (https://www.ebi.ac.uk/gwas/).

CIS evidence in mice: We downloaded CIS coordinates from CCGD (Abbott et al., 2015) (http://ccgd-starrlab.oit.umn.edu/download.php) and mapped them to human hg19 with LiftOver (https://genome.ucsc.edu/cgi-bin/hgLiftOver) from the UCSC browser (Haeussler et al., 2019). Then, we calculated the number of CIS intersecting each IncRNA divided by the gene length with a custom script using BEDtools (Quinlan and Hall, 2010). CIS per Mb values are available in Supplementary Files.

\section{Survival analysis}


Survival plots were constructed using donor-centric whole genome mutations dataset, overall survival data and tumour histology data from UCSC Xena Hub: https://xenabrowser.net/datapages/?cohort=PCAWG\%20(donor\%20centric)\&removeHub=htt ps\%3A\%2F\%2Fxena.treehouse.gi.ucsc.edu\%3A443. The whole genome mutations file was intersected with comprehensive gene annotation v37 (https://www.gencodegenes.org/human/release_38lift37.html) using BEDtools intersect to isolate donors with mutations in IncRNA of interest. Survival of donors with mutations in IncRNA of interest was then compared against the group of donors without mutations in IncRNA of interest using $R$ packages "survival" (https://cran.rproject.org/web/packages/survival/index.html) and "survminer" (https://cran.rproject.org/web/packages/survminer/index.html)

\section{NEAT1 structure and element analysis}

Elements: The window spanning 300 bp around Mut1a and Mut1b (hg19 chr11:65190589-65190888; hg38 chr11:65423118-65423417) was annotated with the program ezTracks (Guillen-Ramirez and Johnson, 2021) using the following datasets as input: (i) structural features: RNA structures conserved in vertebrates (CRS) (Seemann et al., 2017), DNA:RNA triplex structures (Sentürk Cetin et al., 2019), R-Loops lifted over to hg38 (Sanz et al., 2016); (ii) conservation: phastCons conserved elements in 7, 20, 30 and 100-way multiple alignments (Siepel et al., 2005) retrieved from UCSC genome browser (Kent et al., 2002); (iii) high confidence narrow peaks from eCLIP experiments from ENCODE (Davis et al., 2018) (Complete list of accessions is located at Supplementary Table 2).

RBP motif mapping. The 20 bp-padded sequence around Mut1a and Mut1b (hg19 chr11:65190719-65190775) was extracted and then used to generate the sequence of the three distinct alleles WT, only Mut1a and only Mut1b. The three sequences were used as input for de novo RBP motif matching in the web servers RBPmap (Paz et al., 2014) using the option Genome: other and all Human/Mouse motifs) and RBPDB (Cook et al., 2011) (using the default score threshold, 0.8). Outputs were manually parsed and further processed using an in-house Python script.

SNP structural impact analysis. Sequences for the window spanning $300 \mathrm{bp}$ around each mutation target were extracted. Then, only substitutions were kept and encoded according to their relative position and submitted to the MutaRNA web server (Miladi et al., 2020), which also reports scores from RNAsnp (Sabarinathan et al., 2013).

\section{Cell culture}


HeLa, HEK 293T and HCT116 were a kind gift from Roderic Guigo's lab (CRG, Barcelona). The MRC5-SV cells were provided by the group of Ronald Dijkmanthe (Institute of Virology and Immunology, University of Bern) and the HN5 tongue squamous cell carcinoma cells by Jeffrey E. Myers (MD Anderson) to Y. Zimmer. All the cell lines were authenticated using Short Tandem Repeat (STR) profiling (Microsynth Cell Line Typing) and tested negative for mycoplasma contamination.

HeLa, HN5 and HEK 293T cell lines were cultured at $37^{\circ} \mathrm{C}$ in $5 \% \mathrm{CO} 2$ in Dulbecco's Modified Eagle's Medium high-glucose (Sigma) supplemented with: 10\% FBS (Gibco), 1\% LGlutamine (ThermoFisher), 100 I.U./mL of Penicillin/Streptomycin (Thermo Fisher).

HCT-116 and MRC5-SV were cultured in McCoy (Sigma) and EMEM (Sigma), respectively, both supplemented with 10\% FBS (Gibco), 1\% L-Glutamine (ThermoFisher), 100 I.U./mL of Penicillin/Streptomycin (Thermo Fisher). SNU-475 (ATCC) and HuH7 (Cell Line Service) hepatocellular carcinoma cell lines were cultured at $37^{\circ} \mathrm{C}$ in $5 \% \mathrm{CO} 2$ in RPMI-1640,

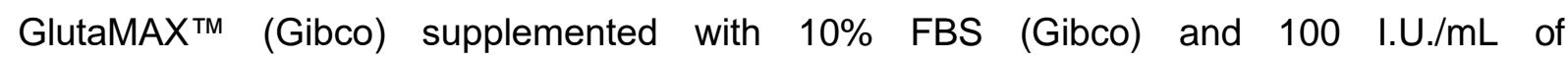
Penicillin/Streptomycin (Thermo Fisher).

\section{Gene overexpression and knockdown experiments}

Both the wild-type and mutated IncRNA spliced sequences were synthesized by Gene Universal Inc, into pcDNA3.1 vector backbone. Control pcDNA3.1 plasmids contained the sequence of enhanced green fluorescent protein (EGFP).

Overexpression in HN5 cells: For each transfection $1.6 \mathrm{ug}$ of plasmid DNA has been incubated for 20 minutes with $4 \mu \mathrm{l}$ of Lipofectamine 2000 transfection reagent (Invitrogen) in $0.2 \mathrm{ml}$ of OptiMEM media (Gibco) and added to the cells cultured in a 6-well plate. As all plasmids contain G418 resistance gene, cells were cultured in $2.5 \mathrm{mg} / \mathrm{ml}$ of G418 (Gibco) $48 \mathrm{~h}$ after transfection.

Overexpression in $\mathrm{HuH} 7$ cells: For each transfection, $100 \mathrm{ng}$ of plasmid DNA were incubated for 20 minutes with $0.15 \mu \mathrm{l}$ Lipofectamine 3000 and $0.2 \mu \mathrm{l} 3000$ transfection reagent (Invitrogen) in $10 \mu \mathrm{LPMI}-1640$, GlutaMAX ${ }^{\mathrm{TM}}$ (Gibco) and added on top of $2000 \mathrm{HuH} 7$ cells cultured in a 96-well plate. Transfection efficiency was measured with qPCR after 120h. Knockdown in SNU-475 and HuH7 cells: For the transfections, $10 \mathrm{nM}$ of each ASO were

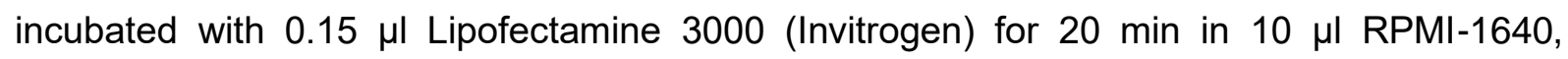
GlutaMAX $^{\mathrm{TM}}$ (Gibco) and added on top of $2000 \mathrm{SNU}-475$ or HuH7 cells cultured in a 96-well plate. Transfection efficiency was measured with qPCR after $144 \mathrm{~h}$.

\section{Crystal violet staining}


Cells were dissociated with $0.05 \%$ trypsin-EDTA (Gibco), resuspended in complete media and counted in Neubauer chamber. Subsequently, 1000 cells per well were plated in a 6 -well plate, cultured for one week and stained in a $2 \%$ Crystal violet (Sigma) solution. The area percentage covered with cells was analysed using ImageJ (\%Area). Data analysis was conducted in Graphpad Prism version 8.0.1. One-way ANOVA was used to determine statistical significance, alpha=0.05.

\section{Proliferation assay - SNU-475 and HuH7}

After transfection, the proliferative capacity of SNU-475 and HuH7 was measured every $24 \mathrm{~h}$ by resazurin assay. Briefly, Resazurin sodium salt (Sigma) was added to each well to reach a final concentration of $3 \mu \mathrm{M}$ and was incubated at $37^{\circ} \mathrm{C}$ for $2 \mathrm{~h}$. Absorbance was measured with Tecan Spark Plate Reader at $545 \mathrm{~nm}$ and $590 \mathrm{~nm}$.

\section{CRISPR sgRNA design and cloning}

CRISPR activation in HeLa cells was performed as described by Sanson and colleagues (Sanson et al., 2018). sgRNAs were designed using the GPP sgRNA Designer CRISPRa from the Broad Institute (https://portals.broadinstitute.org/gpp/public/). For each sgRNA, forward and reverse DNA oligos were synthesized introducing the BsmB1 overhangs. The two oligos were phosphorylated with the Anza TM T4 PNK Kit (Thermofisher) according to the manufacturer instructions in a $10 \mu \mathrm{l}$ final volume. The phosphorylation/annealing reaction was set up in a thermocycler at $20^{\circ} \mathrm{C}$ for $15 \mathrm{~min}$, followed by $95^{\circ} \mathrm{C}$ for $5 \mathrm{~min}$ and then ramp down to $25^{\circ} \mathrm{C}$ at $5^{\circ} \mathrm{C} / \mathrm{min}$ rate. For ligation of annealed oligos into the pXPR_502 backbone (Addgene \#96923), the plasmid was first digested and dephosphorylated with FastDigest $\mathrm{BsmBI}$ and FastAP (Thermofisher) at $37^{\circ} \mathrm{C}$ for 2 hrs. Ligation reaction was carried out with the Rapid DNA Ligation Kit (Thermo) according to the manufacturer instructions.

sgRNAs targeting NEAT1 were designed using the GPP sgRNA Designer CRISPRKo from the Broad Institute (https://portals.broadinstitute.org/gpp/public/), and cloned into the pDECKO backbone (Addgene \#78534) as described above.

\section{Lentivirus production}


For lentivirus production, HEK293T cells $\left(2.5 \times 10^{\wedge} 6\right)$ were seeded in poly-L-lysine coated $100 \mathrm{~mm}$ culture dishes $24 \mathrm{hrs}$ prior to transfection. Cells were then co-transfected in serum-free medium with $12.5 \mu \mathrm{g}$ of the plasmid of interest (Lenti dCAS-VP64_Blast plasmid or sgRNA-containing pXPR_502 or pDECKO), $4 \mu \mathrm{g}$ of the envelope-encoding plasmid pVSVg (Addgene 12260) and $7.5 \mu \mathrm{g}$ of the packaging plasmid psPAX2 (Addgene 8454) with Lipofectamine 2000 (ThermoFisher) according to the manufacturer instructions. After 4-6 hrs the medium was replaced with complete DMEM. Virus-containing supernatant was collected after 24, 48 and 72 hours post-transfection. The three harvests were pooled and centrifuged at $3000 \mathrm{rpm}$ for $15 \mathrm{~min}$ to remove cells and debris. The supernatant was collected, and for every four volumes, one volume of cold PEG-it Virus Precipitation Solution was added. The mix was refrigerated overnight at $4^{\circ} \mathrm{C}$ and centrifuged at $1500 \times \mathrm{g}$ for $30 \mathrm{~min}$ at $4^{\circ} \mathrm{C}$. The supernatant was discarded, and the sample centrifuged at $1500 \times \mathrm{g}$ for $5 \mathrm{~min}$. The lentiviral pellet was suspended in cold, sterile PBS, aliquoted into cryogenic vials and stored at $-70^{\circ} \mathrm{C}$.

\section{Lentivirus transduction}

CRISPRKo: For the generation and transduction of Cas9-expressing cell lines, HeLa, HCT116 and MRC5-SV Cas9 were incubated for $24 \mathrm{hrs}$ with culture medium containing concentrated viral preparation carrying pLentiCas9-T2A-BFP and $8 \mu \mathrm{g} / \mathrm{ml}$ Polybrene. $24 \mathrm{hrs}$ post-infection, antibiotic selection was induced by supplementing the culturing medium with 4 $\mu \mathrm{g} / \mathrm{ml}$ blasticidin (Thermofisher) for 5 days. Blasticidin selected cells were subjected to 3 rounds of fluorescence-activated cell sorting (FACS) to isolate high BFP-expressing cells.

CRISPRa: For the generation and transduction of dCas9-expressing cell lines, HeLa cells were incubated for $24 \mathrm{hrs}$ with culture medium containing concentrated viral preparation carrying pLenti dCas9-T2A-BFP-VP64 and $8 \mu \mathrm{g} / \mathrm{ml}$ Polybrene. Cells underwent FACS sorting to enrich for high BFP expressing cells.

sgRNAs: pLentiCas9-T2A-BFP or dCas9-T2A-BFP-VP64 stable cell line were seeded into 6 well plates at $10^{\wedge} 6$ cells per well and supplemented with sgRNAs pDECKO or pXPR_502 lentiviral preps, respectively, and spinfected in the presence of polybrene $(2 \mu \mathrm{g} / \mathrm{ml})$ for $95 \mathrm{~min}$ at $2000 \mathrm{rpm}$ at $37{ }^{\circ} \mathrm{C}$, followed by medium replacement. $24 \mathrm{hrs}$ post-infection, antibiotic selection was induced by supplementing the culturing medium with $2 \mu \mathrm{g} / \mathrm{ml}$ puromycin (Thermofisher) for at least 3 days.

\section{RT-qPCR gene expression analysis}


HeLa cells were lysed, and total RNA was extracted by using the Quick-RNA ${ }^{\text {TM }}$ Miniprep Kit (Zymo Research). For each sample, RNA was retro-transcribed into cDNA by using the GoScript ${ }^{\mathrm{TM}}$ Reverse Transcription System (Promega) and the expression of the target gene was assessed through Real-Time PCR with the GoTaq® qPCR Master Mix. To this purpose target-specific mostly intron-spanning primers (Supplementary Table 1) were designed by using the online tool Primer 3 version 4.1.0.

\section{Cell viability assay}

After puromycin selection, cells expressing controls and candidates' guides were collected and seeded in 96-well plates in at least 3 technical replicates for each time point (3000 cells per well). Proliferation assay was performed using the Cell-Titer Glo 2.0 (Promega) reagent according to the manufacturer instructions. Luminescence was measured with the INFINITE 200 PRO series TECAN reader instrument. Time point 0 (T0) reading was performed 4-5 hours after cell seeding.

\section{1:1 competition assay}

HeLa, HCT116 and MRC5-SV cells were infected with pDECKO lentiviruses expressing fluorescent proteins. Control plasmids containing sgRNAs targeting AAVS1 expressed GFP protein (pgRNAs-AASV1-GFP+), while the sgRNAs targeting the different regions of NEAT1 expressed mCherry. After infection, and seven days of puromycin $(2 \mu \mathrm{g} / \mathrm{ml})$ selection, GFP and mCherry cells were mixed 1:1 in a six-well plate (150,000 cells). Cell counts were analysed by LSR II SORP instrument (BD Biosciences) and analysed by FlowCore software.

\section{Pooled competition assay}

Screen: HeLa cells stably expressing sgRNAs targeting NEAT1 Reg2, Reg3, Reg4, Reg5 and KO, and HeLa cells stably expressing sgRNAs Control1 and Control2 were counted and mixed in the following ratio 10:10:10:10:25:25. At Day 0, 2M cells were collected, while $2 \mathrm{M}$ were plated and passaged every 2-3 days. Cells were harvested at 7, 14, 21 and 28 days for gDNA extraction. The experiment was conducted in six biological replicates. 
Genomic DNA preparation and sequencing: Genomic DNA (gDNA) was isolated using the Blood \& Cell Culture DNA Mini (<5e6 cells) Kits (Qiagen, cat. no. 13323) as per the manufacturer's instructions. The gDNA concentrations were quantified by Nanodrop. For PCR amplification, $1 \mu \mathrm{g}$ of gDNA was amplified in a $200 \mu$ reaction using Q5® High-Fidelity $2 X$ Master Mix (NEB \#M0491). PCR master mix (100 $\mu \mathrm{l}$ Q5, and $10 \mu \mathrm{l}$ of Forward universal primer, and $10 \mu \mathrm{l}$ of a uniquely barcoded $\mathrm{P} 7$ primer (both stock at $10 \mu \mathrm{M}$ concentration). PCR cycling conditions: an initial $30 \mathrm{sec}$ at $98^{\circ} \mathrm{C}$; followed by $10 \mathrm{sec}$ at $98^{\circ} \mathrm{C}, 30 \mathrm{sec}$ at $68^{\circ} \mathrm{C}, 20 \mathrm{sec}$ at $72{ }^{\circ} \mathrm{C}$, for 22 cycles; and a final 2 min extension at $72^{\circ} \mathrm{C}$. NGS primers are listed in Supplementary Table 1. PCR products were purified with Agencourt AMPure XP SPRI beads according to manufacturer's instructions (Beckman Coulter, cat. no. A63880). Purified PCR products were quantified using the Qubit ${ }^{\mathrm{TM}}$ dsDNA HS Assay Kit (ThermoFisher, cat. no. Q32854). Samples were sequenced on a HiSeq2000 (Illumina) with paired-end 150 bp reads. The raw sequencing reads from individual samples were analysed by using a custom shell script to count the number of reads containing each sgRNA. The sgRNA counts were then normalized over the T0 and Control2.

\section{Deep sequencing to determine indel spectrum}

Genomic DNA was extracted using the Blood \& Cell Culture DNA Mini ( $<5 \mathrm{M}$ cells) Kits (Qiagen, cat. no. 13323) as per the manufacturer's instructions. To prepare samples for Illumina sequencing, a two-step PCR was performed to amplify the different regions of NEAT1. For each sample, we performed two separate 100 ul reactions ( 25 cycles each) with $250 \mathrm{ng}$ of input gDNA using Q5 MASTER MIX (NEB \#M0491) and the resulting products were pooled (PCR reaction: $30 \mathrm{sec}$ at $98^{\circ} \mathrm{C}$; followed by $10 \mathrm{sec}$ at $98^{\circ} \mathrm{C}, 30 \mathrm{sec}$ at $68^{\circ} \mathrm{C}, 20 \mathrm{sec}$ at $72^{\circ} \mathrm{C}$, for 22 cycles; and a final 2 min extension at $72{ }^{\circ} \mathrm{C}$ ). PCR amplicons were purified using solid phase reversible immobilization (SPRI) beads, run on a $1.5 \%$ agarose gel to verify size and purity, and quantified by Qubit Fluorometric Quantitation (Thermo Fisher Scientific). The resulting DNA was used for reamplification with primers containing Illumina adaptors using the Q5 master Mix. Illumina adaptors and index sequences were added to $100 \mathrm{ng}$ of purified PCR amplicon (PCR reaction: $30 \mathrm{sec}$ at $98^{\circ} \mathrm{C}$; followed by $10 \mathrm{sec}$ at $98^{\circ} \mathrm{C}, 30 \mathrm{sec}$ at $68^{\circ} \mathrm{C}, 20 \mathrm{sec}$ at $72^{\circ} \mathrm{C}$, for 8 cycles; and a final 2 min extension at $72^{\circ} \mathrm{C}$ ).

\section{RNA-FISH and immunofluorescence}


HeLa cells grown on coverslips were fixed using 4\% paraformaldehyde and permeabilised by $70 \%$ ethanol overnight. For RNA-FISH, Stellaris ${ }^{\circledR}$ FISH Probes, targeting Human NEAT1 Middle Segment, labelled with FAM dye (1:100, Biosearch Technologies) were used and the procedure was carried out according to the manufacturer's instructions. Cells nuclei were counterstained with 1:15,000 DAPI (4',6-diamidino-2-phenylindole) at room temperature and then mounted onto slides by using the VectaShield (Vector Laboratories) mounting media. Fluorescence signals were imaged at 100x (UPLS Apo 100×/1.40) using the DeltaVision Elite Imaging System and Softworx software (GE Healthcare). Images were acquired as Z-stacks, subjected to deconvolution, and projected with maximum intensity. Images were processed using a custom CellProfiler pipeline to determine paraspeckle number and size.

\section{Soft agar assay}

The soft agar colony formation assay was performed as previously described (Borowicz S., et al., 2014). Briefly, the assay was carried out in 6-well plates coated with a bottom layer of $1 \%$ noble agar in $2 X$ DMEM (ThermoFisher) supplemented with: sodium bicarbonate, $10 \%$ FBS (Gibco), 1\% L-Glutamine (ThermoFisher), 100 I.U./ml of Penicillin/Streptomycin (ThermoFisher). Then, 7000 cells were suspended in 2X DMEM and $0.6 \%$ noble agar. The suspension mixture was subsequently applied as the top agarose layer. A layer of growth medium was added over the upper layer of agar to prevent desiccation. The plates were incubated at $37^{\circ} \mathrm{C}$ in $5 \% \mathrm{CO} 2$ for 3 weeks until colonies formed. After 20 days the colonies were stained with $200 \mathrm{ml}$ of MTT [(3-(4,5-dimethylthiazol-2-yl)-2,5-diphenyltetrazolium bromide), (5 mg/ml), Sigma] and incubated for 3 hours at $37^{\circ} \mathrm{C}$. Numbers of colonies were counted using the analysis software ImageJ.

\section{D spheroid assay}


HCT116 stably expressing Cas9-BFP and sgRNA-mCherry targeting NEAT1 locus were FACS sorted to enrich the population BFP+/mCherry+. The cells were allowed to grow for 7 days, then detached, counted and seeded onto Corning® 96-well Flat Clear Bottom White (Corning, cat. no. 3610) in $20 \mu \mathrm{l}$ domes of Matrigel ${ }^{\circledR}$ Matrix GFR, LDEV-free (Corning, cat. no. 356231) and McCoy (Sigma, cat. No. M9309) growth medium (1:1) with a density of 10,000 cells per dome in four technical replicates. Matrigel containing the cells was allowed to solidify for an hour in the incubator at $37^{\circ} \mathrm{C}$ before adding 80ul of McCoy growth media on top of the wells. The spheroids were allowed to grow in the incubator at $37^{\circ} \mathrm{C}$ in a humid atmosphere with $5 \% \mathrm{CO} 2$. After $4 \mathrm{~h}$ the number of viable cells in the 3D cell culture was recorded as time point 0 (T0), CellTiter-Glo® 3D Cell Viability Assay (Promega, cat. no. G9682) was added to the wells, following the manufacturer's instructions for the reading with the Tecan Infinite $₫ 200$ Pro. After one week the measurement was repeated.

\section{RNA pull-down and Mass Spectrometry}

RNA pull-down analysis was performed as previously described (Marín-Béjar O, Huarte M., 2015). Briefly, wild-type and mutant NEAT1 RNA fragments were transcribed in vitro using HiScribe $^{\text {TM }}$ T7 High Yield RNA Synthesis Kit (NEB, \#E2040S) and labelled with Biotin using Biotin RNA Labelling Mix (Roche, \#11685597910) according to the manufacturers' instructions. Biotinylated RNA (10 pmol) was denatured for 10 min at $65^{\circ} \mathrm{C}$ in RNA Structure Buffer (10 mM tris- $\mathrm{HCl}, 10 \mathrm{mM} \mathrm{MgCl}_{2}$, and $100 \mathrm{mM} \mathrm{NH}_{4} \mathrm{C} 1$ ) and slowly cool down to $4{ }^{\circ} \mathrm{C}$. Nuclear fractions were collected as described previously (Carlevaro-Fita J., et al., 2018) and precleared for $30 \mathrm{~min}$ at $4{ }^{\circ} \mathrm{C}$ using Streptavidin Mag Sepharose® (Sigma, \#GE28-9857-99) and NT2 Buffer [50 mM tris- $\mathrm{HCl}(\mathrm{pH} 7.4), 150 \mathrm{mM} \mathrm{NaCl}, 1 \mathrm{mM} \mathrm{MgCl} 2,0.05 \% \mathrm{NP}-40,1 \mathrm{mM}$ DTT, 20 mM EDTA, 400 mM vanadyl-ribonucleoside, RNase inhibitor ( $0.1 \mathrm{U} / \mu \mathrm{l}$; Promega), and Ix protease inhibitor cocktail (Sigma)]. The precleared nuclear lysates (2 mg) were incubated with purified biotinylated RNA in NT2 buffer along with Yeast tRNA $(20 \mu \mathrm{g} / \mathrm{ml}$; Thermo Fisher Scientific \#AM7119) with gentle rotation for 1.5 hours at $4^{\circ} \mathrm{C}$. Washed Streptavidin Magnetic Beads were added to each binding reaction and further incubated at $4{ }^{\circ} \mathrm{C}$ for $1 \mathrm{~h}$ to precipitate the RNA-protein complexes. Beads were washed briefly five times with NT2 Buffer, and the retrieved proteins were then subjected to mass spectrometry analysis, performed by the Proteomics \& Mass Spectrometry Core Facility (PMSCF) of the University of Bern, Switzerland, using MaxQuant software for protein identification and quantification.

\section{Mass Spectrometry Data Processing}

Intensity Based Absolute Quantification (BAQ) and label-free quantitation (LFQ) intensities from the MaxQuant output were used for quantitative within-sample comparisons and fold-enrichment between-sample comparisons respectively. A protein was considered 
enriched / depleted in a sample condition if its intensity was at least 2-fold greater / lesser than in the reference condition (proteins not detected in one of the conditions are imputed with the lowest value for that sample by MaxQuant). Additionally, the resulting lists of proteins were filtered for nuclear localization (Uhlen et al., 2015) to exclude potential false positives. To calculate the significance of the overlap with known NEAT1 binding proteins (Huang et al., 2020; Spiniello et al., 2018; West et al., 2014) and known paraspeckle proteins (McCluggage and Fox, 2021) a hypergeometric test was applied to the background of all nuclear proteins ( $n=6758$ ). STRING was used for interaction analysis (physical subnetwork, minimum interaction score $=0.4$, max number of direct interactors $=10$ ) and $\mathrm{GO}$ term enrichment analysis (Szklarczyk et al., 2019). Visualization of the results was done with $\mathrm{R}$ version 4.1.1 and BioRender.com. 


\section{Figure Legends}

\section{Figure 1}

A) ExInAtor2 accepts input in the form of maps of single nucleotide variants (SNVs) from cohorts of tumour genomes. Two signatures of positive selection are evaluated and compared to simulated local background distributions, to evaluate statistical significance. The two significance estimates are combined using Fisher's method.

B) Summary of the primary tumour datasets used here, obtained from Pancancer Analysis of Whole Genomes (PCAWG) project.

C) A filtered IncRNA gene annotation was prepared, and combined with a set of curated cancer IncRNAs from the Cancer LncRNA Census (Vancura et al., 2021).

\section{Figure 2}

A) The list of driver discovery methods to which ExInAtor2 was compared. The signatures of positive selection employed by each method are indicated to the right. PCAWGc indicates the combined driver prediction method from Pan-Cancer Analysis of Whole Genomes (PCAWG), which integrates all ten methods.

B) Benchmark gene sets. LncRNAs (blue) were divided in positives and negatives according to their presence or not in the Cancer LncRNA Census (Vancura et al., 2021), respectively, and similarly for protein-coding genes in the Cancer Gene Census (Sondka et al., 2018).

C) Comparing performance in terms of precision in identifying true positive known cancer IncRNAs from the CLC dataset, using PCAWG Pancancer cohort. $x$-axis: genes sorted by increasing $p$-value. $y$-axis: precision, being the percentage of true positives amongst cumulative set of candidates at increasing $p$-value cutoffs. Horizontal black line shows the baseline, being the percentage of positives in the whole list of tested genes. Coloured dots represent the precision at cutoff of $q \leq 0.1$. Inset: Performance statistics for cutoff of $q \leq 0.1$.

D) Driver prediction performance for all methods in all PCAWG cohorts. Cells show the F1score of each driver method ( $x$-axis) in each cohort ( $y$-axis). Grey cells correspond to cohorts where the method was not run. The bar plot on the top indicates the total, non-redundant number of True Positives (TP) and False Positives (FP) calls by each method. Driver methods are sorted from left to right according to the F1-score of unique candidates.

E) Evaluation of $p$-value distributions for driver IncRNA predictions. Quantile-quantile plot (QQplot) shows the distribution of observed vs expected -log10 $p$-values for each method run on the PCAWG Pancancer cohort. The Mean Log-Fold Change (MLFC) quantifies the difference between observed and expected values (Methods).

\section{Figure 3}


A) "Oncoplot" overview of driver IncRNA analysis in PCAWG primary tumours. Rows: 17 candidate driver IncRNAs at cutoff of $q \leq 0.1$. Columns: 2580 tumours.

B) LncRNA candidates across all cohorts. Rows: Cohorts where hits were identified. Columns: 17 candidate driver IncRNAs. "Known" IncRNAs are part of the literature-curated Cancer LncRNA Census (CLC2) dataset (Vancura et al., 2021). Functional labels (oncogene / tumour suppressor / both) were also obtained from the same source.

C) Intersection of candidate driver IncRNAs identified in PCAWG primary tumours, Hartwig Medical Foundation (HMF) metastatic tumours and the CLC2 set. Statistical significance was estimated by Fisher's exact test.

D) Genomic features of driver IncRNAs. Each plot displays the values of indicated features for 17 candidate driver IncRNAs (blue) and all remaining tested IncRNAs (non-candidates, grey). Significance was calculated using Wilcoxon test. For each comparison, the ratio of means was calculated as (mean of candidate values / mean of non-candidate values). See Methods for more details.

E) Clinical features of driver IncRNAs. Each point represents the indicated feature. $y$-axis: log2transformed ratio of the mean candidate value and mean non-candidate value. $x$-axis: The statistical significance of candidate vs non-candidate values, as estimated by Wilcoxon test and corrected for multiple testing. See Methods for more details.

\section{Figure 4}

A) The genomic locus of hepatocellular carcinoma (HCC) candidate driver IncRNA MILC. Also shown are SNVs from PCAWG and Hartwig (HMF). The SNVs included in the mutated version of the plasmids are indicated in the grey boxes.

B) Antisense oligonucleotides (ASOs) were transfected into cells to knock down expression of target IncRNAs.

C) Reverse transcription quantitative polymerase chain reaction (qRT-PCR) measurement of RNA levels in $\mathrm{HuH} \mathrm{HCC}$ cells after transfection of control ASO, or two different ASOs targeting MILC. Statistical significance was estimated using one-sided Student's $t$-test with $n=3$ independent replicates.

D) Populations of ASO-transfected cells were measured at indicated time points. Each measurement represents $n=3$ independent replicates.

E) Overview and performance of CRISPR-activation (CRISPRa) targeting MILC. On the right, qRT-PCR measurements of RNA levels with indicated sgRNAs in HeLa cells. Values were normalised to the housekeeping gene HPRT1 and to a control sgRNA targeting the AAVS1 locus. Values represent $n=3$ independent replicates. 
bioRxiv preprint doi: https://doi.org/10.1101/2021.11.06.467555; this version posted January 11, 2022. The copyright holder for this preprint (which was not certified by peer review) is the author/funder, who has granted bioRxiv a license to display the preprint in perpetuity. It is made available under aCC-BY-NC-ND 4.0 International license.

F) The effect of CRISPRa on HeLa cells' viability, as measured by Cell Titre Glo reagent. Values represent $n=6$ independent replicates, and statistical significance was estimated by comparison to the Control sgRNA by paired $t$-test at the $48 \mathrm{hrs}$ timepoint.

G) Plasmids expressing spliced MILC sequence, in wild-type (WT) or mutated (Mut) form were transfected into HuH cells. The steady state levels of RNA were measured by qRT-PCR and normalised to cells transfected with similar EGFP-expressing plasmid. Values represent $n=3$ independent replicates, each one with 6 technical replicates.

H) Populations of plasmid-transfected cells were measured at indicated timepoints. Statistical significance was estimated by one-sided Student's $t$-test based on $n=3$ independent replicates.

I) The genomic locus of head and neck cancer candidate driver IncRNA MIHNC. Also shown are SNVs from PCAWG and Hartwig. The SNVs included in the mutated version of the plasmids are indicated in the grey boxes.

K) Plasmids expressing spliced MIHNC sequence, in wild-type (WT) or mutated (Mut) form were transfected into HN5 cells. The steady state levels of RNA were measured by qRT-PCR and normalised to cells transfected with similar EGFP-expressing plasmid. Values represent $\mathrm{n}=3$ independent replicates.

J) Results of colony formation assay in HN5 cells. Values indicate the percent of well area covered. Statistical significance was estimated using One-way ANOVA has been used to determine statistical significance, based on 18 culture wells.

\section{Figure 5}

A) Overview of the experimental strategy to simulate tumour mutations in the NEAT1 IncRNA gene by wild-type Cas9 protein.

B) A detailed map of the six NEAT1 target regions and $15 \mathrm{sgRNAs}$. Paired gRNAs used for the deletion of NEAT1_1 are indicated as KO- sgRNA1 and KO- sgRNA2. Previously described functional regions of NEAT1 are indicated below, according to the publication of Yamazaki and colleagues (Yamazaki et al., 2018).

C) Analysis of mutations created by Cas 9 recruitment. The target region was amplified by PCR and sequenced. The frequency, size and nature of resulting DNA mutations are plotted.

D) Competition assay to evaluate fitness effects of mutations. Above: Rationale for the assay. Labelled mutated (mCherry, red) and control (GFP, green) cells are mixed in equal proportions at the start of the experiment. At successive timepoints their red/green ratio is measured by flow cytometry, and this value is used to infer fitness effects. Below: Red/green ratios for indicated mutations. "Control1/2" indicate sgRNAs targeting intergenic regions. "KO" indicates paired sgRNAs designed to delete the entire NEAT1_1 region. Separate experiments were performed in HeLa and HCT116 cells. $n=4$ replicated experiments were performed, and statistical significance was estimated by linear regression model. 
E) Upper panel: Setup of mini CRISPR fitness screen. HeLa cells are infected with lentivirus carrying defined mixtures of sgRNAs. The sgRNA sequences are amplified and sequenced at defined timepoints. Changes in abundance reflect effects on cell fitness. Lower panel: Abundances of displayed sgRNAs, normalised to the Control 2 negative control. $n=4$ independent experiments were performed, and statistical significance was estimated by linear regression model.

F) HCT116 cells were cultured as spheroids and their population measured. $n=4$ replicated experiments were performed, and statistical significance was estimated using Student's onesided $t$-test.

G) As for Panel D, but with non-transformed MRC5 lung fibroblast cells at timepoint Day 14 . Statistical significance was estimated by one-sided Student's t-test based on $n=3$ independent replicates.

H) MRC5 cells were seeded in soft agar, and the area of colonies at 3 weeks were calculated. The mean of $n=2$ replicated experiments are shown.

I) The survival time of 184 lymphoid cancer patients from PCAWG is displayed. Patients were stratified according to whether they have $\geq 1$ SNVs in the NEAT1 gene.

\section{Figure 6}

A) Normalised steady state RNA levels of NEAT1, as estimated using primers for the total NEAT1 region. Statistical significance was estimated using Student's one-sided $t$-test. Pvalues $\geq 0.05$ are not shown.

B) As for Panel A, but using primers for NEAT1_2.

C) Representative images from fluorescence in situ hybridisation (FISH) visualisation of NEAT1 in HeLa cells expressing sgRNAs for Control 2 and NEAT1 Region 2.

D) Counts of paraspeckles in HeLa cells treated with indicated sgRNAs, normalised and compared to Control 2 cells. Values were obtained from $80-100$ cells per replicate. $\mathrm{N}=5$ biological replicates. Statistical significance was estimated using paired t-test.

E) As for Panel D, but displaying paraspeckle size.

F) Schematic representation of the mechanism of action of driver mutations within NEAT1 sequence.

G) Sequences of biotinylated probes used for mass-spectrometry analysis of NEAT1interacting proteins.

H) Proteins detected by wild-type (WT) NEAT1 probe, filtered for nuclear proteins only, are ranked by intensity and labelled when intersecting databases of previously-detected NEAT1interacting proteins (green) and paraspeckle proteins (orange). Statistical significance was calculated by hypergeometric test (to background of all nuclear proteins $n=6758$ ). 
I) Histogram shows differential detection of proteins comparing mutated (Mut) and wild-type (WT) probes. Dotted lines indicate log2 fold-change cutoffs of $-1 /+1$.

J) STRING interaction network based on a subset of the proteins lost upon mutation (grey borders) interacting with the RNA polymerase II core complex. 


\section{Supplementary Figure Legends \\ Supplementary Figure 1}

A) Graphic representation of the Mutational Burden module of ExInAtor2. Genes are divided in exons and background regions (including introns and flanking regions defined by the user). The number of real exonic mutations is calculated ('observed'). Mutations in both exons and background are randomly shuffled, maintaining the overall trinucleotide content, a number of times indicated by the user (10,000 as example), and the number of exonic mutations in each iteration is recorded. The $p$-value is calculated by counting how many shuffled values are higher or equal than the real mean score, divided by the total number of shuffles performed.

B) Graphic representation of the Functional Impact module of ExInAtor2. Only exonic regions are considered. The mean functional impact score is calculated for all mutated positions. In a number of simulations defined by the user (10,000 as example), mutations are randomly shuffled along the exons while maintaining the trinucleotide signature, and the mean functional impact score is recorded. The $p$-value is calculated by counting how many shuffled values are higher or equal than the real mean score, divided by the total number of shuffles.

\section{Supplementary Figure 2}

A) Evaluation of $p$-value distributions for protein-coding genes. Quantile-quantile plot (QQ-plot) shows the distribution of observed vs expected -log10 $p$-values from each methods across all cohorts. The Mean Log-Fold Change (MLFC) quantifies the difference between observed and expected values (Methods).

B) Benchmark in PCAWG Pancancer dataset for protein-coding genes. $x$-axis represents genes sorted increasingly by $p$-value for each method. $y$-axis shows the percentage of true positives amongst cumulative set of candidates (precision) at each step of the $x$-axis (precision). Black line shows the baseline, being the percentage of positives in the whole list of tested genes, ie the precision expected by random chance. Coloured dots represent the number of candidates for each method with $q$-value $<=0.1$. Table shows the number of True Positives (TP), False Positives (FP) and F1-score (Methods) for each driver method.

C) Protein-coding benchmark for all PCAWG cohorts. Cells show the F1-score of each driver method ( $x$-axis) in each cohort ( $y$-axis). Grey cells correspond to cohorts where the method was not run. The bar plot at the top indicates the non-redundant total number of True Positives (TP) and False Positives (FP) unique candidates detected across all cohorts, i.e., if a gene is detected in multiple cohorts it is considered only once. Driver methods on the $x$-axis are sorted from left to right according to the F1-score of unique candidates.

D) QQ plots displayed neutral behaviour (MLFC 0.08) of the IncRNA analysis on a set of carefully-randomised pancancer SNVs. 


\section{Supplementary Figure 3}

A) Clinical / disease properties of IncRNA drivers. Displayed are the percentage of IncRNAs that fulfill indicated criteria. LncRNAs are divided into candidate drivers from PCAWG analysis (red), and all other tested IncRNAs (blue). 'Growth-promoting' refer to IncRNAs necessary for proliferation of cancer cell lines discovered by CRISPRi perturbation pooled screens of Liu et al (Liu et al., 2017); 'Transposon insertional mutagenesis' refer to IncRNA genes orthologous to sites carrying tumour-initiating Sleeping Beauty insertions from mouse genome-wide screens (Vancura et al., 2021); 'CRIncRNA' - database of cancer Incrnas (Wang et al., 2018); 'Lnc2cancer' - database of cancer IncRNAs (Ning et al., 2016); 'MiTranscriptome' differentially expressed IncRNAs in tumours (lyer et al., 2015); 'Cancer LncRNA Census 2' (Vancura et al., 2021). Statistical significance was calculated by Fisher's exact test.

B) Statistics of Hartwig Medical Foundation (HMF) tumour SNV data (Priestley et al., 2019).

C) Candidate driver IncRNAs discovered in HMF cohort. ExInAtor2 hits are displayed with a cutoff of FDR<0.1. Numbers inside cells represent the number of exonic SNVs. D) Oncoplot summarising IncRNA SNVs in the HMF cohort.

\section{Supplementary Figure 4}

A) Bulk tissue gene expression for MILC. Data was obtained from GTEXportal.

B) MILC gene locus. The position of the sgRNAs for the CRISPRa are shown.

C) Reverse transcription quantitative polymerase chain reaction (qRT-PCR) measurement of RNA levels in SNU476 HCC cells after transfection of control ASO, or two different ASOs targeting MILC. Statistical significance was estimated using one-sided Student's t-test with $n=3$ independent replicates.

D) Populations of ASO-transfected cells were measured at indicated time points. Each measurement represents $n=3$ independent replicates. Statistical significance was estimated using one-sided Student's t-test with $n=3$ independent replicates at the last time point.

\section{Supplementary Figure 5}

A) We performed deep sequencing to determine the resulting indel distribution arising from targeting Cas9 to Region 2. The reference sequence and the sgRNA are shown on top.

B) Genomic deletion of NEAT1_1 gene using paired gRNAs. The panel shows agarose gel electrophoresis of PCR product (on the left) and a cartoon showing the deletion strategy (on the right) with primers amplifying the NEAT1 target region.

C) The figure shows various genomic features overlapping NEAT1 Region 2 (highlighted). CRS: Conserved RNA Structure (Seemann et al., 2017). Red bars indicate RNA-binding proteins located by eCLIP (Davis et al., 2018). RNA:DNA indicates experimentally-mapped 
bioRxiv preprint doi: https://doi.org/10.1101/2021 11.06.467555; this version posted January 11 2022. The copyright holder for this preprint (which was not certified by peer review) is the author/funder, who has granted bioRxiv a license to display the preprint in perpetuity. It is made available under aCC-BY-NC-ND 4.0 International license.

chromatin interacting domains (Sentürk Cetin et al., 2019). Pink bars indicate conserved regions from PhastCons (Siepel et al., 2005). 


\section{References}

Abbott, K.L., Nyre, E.T., Abrahante, J., Ho, Y.-Y., Isaksson Vogel, R., and Starr, T.K. (2015). The Candidate Cancer Gene Database: a database of cancer driver genes from forward genetic screens in mice. Nucleic Acids Res. 43, D844-D848.

Adriaens, C., Standaert, L., Barra, J., Latil, M., Verfaillie, A., Kalev, P., Boeckx, B., Wijnhoven, P.W.G., Radaelli, E., Vermi, W., et al. (2016). P53 induces formation of NEAT1 IncRNAcontaining paraspeckles that modulate replication stress response and chemosensitivity. Nat. Med. 22, 861-868.

Adriaens, C., Rambow, F., Bervoets, G., Silla, T., Mito, M., Chiba, T., Asahara, H., Hirose, T., Nakagawa, S., Jensen, T.H., et al. (2019). The long noncoding RNA NEAT1_1 is seemingly dispensable for normal tissue homeostasis and cancer cell growth. Rna 25, 1681-1695.

Agrawal, S. (2020). RNA Therapeutics Are Stepping Out of the Maze. Trends Mol. Med. 26, 1061-1064.

Aguirre, A.J., Meyers, R.M., Weir, B.A., Vazquez, F., Zhang, C.Z., Ben-David, U., Cook, A., Ha, G., Harrington, W.F., Doshi, M.B., et al. (2016). Genomic Copy Number Dictates a GeneIndependent Cell Response to CRISPR/Cas9 Targeting. Cancer Discov. 6, 914-929.

AH, F., YW, L., AK, L., CE, L., J, A., M, M., and AI, L. (2002). Paraspeckles: a novel nuclear domain. Curr. Biol. 12, 13-25.

Akrami, R., Jacobsen, A., Hoell, J., Schultz, N., Sander, C., and Larsson, E. (2013). Comprehensive Analysis of Long Non-Coding RNAs in Ovarian Cancer Reveals Global Patterns and Targeted DNA Amplification. PLoS One 8, e80306.

Anzalone, A. V., Koblan, L.W., and Liu, D.R. (2020). Genome editing with CRISPR-Cas nucleases, base editors, transposases and prime editors. Nat. Biotechnol. 2020387 38, 824844.

Artegiani, B., Hendriks, D., Beumer, J., Kok, R., Zheng, X., Joore, I., Chuva de Sousa Lopes, S., van Zon, J., Tans, S., and Clevers, H. (2020). Fast and efficient generation of knock-in human organoids using homology-independent CRISPR-Cas9 precision genome editing. Nat. Cell Biol. 2020223 22, 321-331. 
Buniello, A., MacArthur, J.A.L., Cerezo, M., Harris, L.W., Hayhurst, J., Malangone, C., McMahon, A., Morales, J., Mountjoy, E., Sollis, E., et al. (2019). The NHGRI-EBI GWAS Catalog of published genome-wide association studies, targeted arrays and summary statistics 2019. Nucleic Acids Res. 47, D1005-D1012.

Campbell, P.J., Getz, G., Korbel, J.O., Stuart, J.M., Jennings, J.L., Stein, L.D., Perry, M.D., Nahal-Bose, H.K., Ouellette, B.F.F., Li, C.H., et al. (2020). Pan-cancer analysis of whole genomes. Nature 578, 82-93.

Carlevaro-Fita, J., A, L., L, F., C, H., D, M.-P., JS, P., and R, J. (2020). Cancer LncRNA Census reveals evidence for deep functional conservation of long noncoding RNAs in tumorigenesis. Commun. Biol. 3.

Castro-Giner, F., Ratcliffe, P., and Tomlinson, I. (2015). The mini-driver model of polygenic cancer evolution. Nat. Rev. Cancer 20151511 15, 680-685.

Cho, S.W., Xu, J., Sun, R., Mumbach, M.R., Carter, A.C., Chen, Y.G., Yost, K.E., Kim, J., He, J., Nevins, S.A., et al. (2018). Promoter of IncRNA Gene PVT1 Is a Tumor-Suppressor DNA Boundary Element. Cell 173, 1398-1412.e22.

Collins, M.A., Bednar, F., Zhang, Y., Brisset, J.-C., Galbán, S., Galbán, C.J., Rakshit, S., Flannagan, K.S., Adsay, N.V., and Magliano, M.P. di (2012). Oncogenic Kras is required for both the initiation and maintenance of pancreatic cancer in mice. J. Clin. Invest. 122, 639.

Cook, K.B., Kazan, H., Zuberi, K., Morris, Q., and Hughes, T.R. (2011). RBPDB: a database of RNA-binding specificities. Nucleic Acids Res. 39, D301-D308.

Corona, R.I., Seo, J.H., Lin, X., Hazelett, D.J., Reddy, J., Fonseca, M.A.S., Abassi, F., Lin, Y.G., Mhawech-Fauceglia, P.Y., Shah, S.P., et al. (2020). Non-coding somatic mutations converge on the PAX8 pathway in ovarian cancer. 11.

Davis, C.A., Hitz, B.C., Sloan, C.A., Chan, E.T., Davidson, J.M., Gabdank, I., Hilton, J.A., Jain, K., Baymuradov, U.K., Narayanan, A.K., et al. (2018). The Encyclopedia of DNA elements (ENCODE): Data portal update. Nucleic Acids Res. 46, D794-D801.

Elliott, K., and Larsson, E. (2021). Non-coding driver mutations in human cancer. Nat. Rev. Cancer 21, 500-509.

Frankish, A., Diekhans, M., Ferreira, A.M., Johnson, R., Jungreis, I., Loveland, J., Mudge, J.M., Sisu, C., Wright, J., Armstrong, J., et al. (2019). GENCODE reference annotation for the human and mouse genomes. Nucleic Acids Res. 47, D766-D773. 
Fujimoto, A., Furuta, M., Totoki, Y., Tsunoda, T., Kato, M., Shiraishi, Y., Tanaka, H., Taniguchi, H., Kawakami, Y., Ueno, M., et al. (2016). Whole-genome mutational landscape and characterization of noncoding and structural mutations in liver cancer. Nat. Genet. 48, 500509.

Gandhi, M., Caudron-Herger, M., and Diederichs, S. (2018). RNA motifs and combinatorial prediction of interactions, stability and localization of noncoding RNAs. Nat. Struct. Mol. Biol. 25, 1070-1076.

Gloss, B.S., and Dinger, M.E. (2018). Realizing the significance of noncoding functionality in clinical genomics. Exp. Mol. Med. 2018508 50, 1-8.

Guillen-Ramirez, H.A., and Johnson, R. (2021). ezTracks v0.1.0.

Haapaniemi, E., Botla, S., Persson, J., Schmierer, B., and Taipale, J. (2018). CRISPR-Cas9 genome editing induces a p53-mediated DNA damage response. Nat. Med. 24, 927-930.

Haeussler, M., Zweig, A.S., Tyner, C., Speir, M.L., Rosenbloom, K.R., Raney, B.J., Lee, C.M., Lee, B.T., Hinrichs, A.S., Gonzalez, J.N., et al. (2019). The UCSC Genome Browser database: 2019 update. Nucleic Acids Res. 47, D853-D858.

Hornshøj, H., MM, N., NA, S.-A., MP, Ś., M, J., T, M., R, S., M, K., T, Ø., A, H., et al. (2018). Pan-cancer screen for mutations in non-coding elements with conservation and cancer specificity reveals correlations with expression and survival. NPJ Genomic Med. 3.

Hu, X., Y, F., D, Z., SD, Z., Z, H., J, G., Y, Z., L, Y., X, Z., LP, W., et al. (2014). A functional genomic approach identifies FAL1 as an oncogenic long noncoding RNA that associates with BMI1 and represses p21 expression in cancer. Cancer Cell 26, 344-357.

Huang, J., Sachdeva, M., Xu, E., Robinson, T.J., Luo, L., Ma, Y., Williams, N.T., Lopez, O., Cervia, L.D., Yuan, F., et al. (2020). The long noncoding RNA NEAT1 promotes sarcoma metastasis by regulating RNA splicing pathways. Mol. Cancer Res. 18, 1534-1544.

Hutchinson, J.N., Ensminger, A.W., Clemson, C.M., Lynch, C.R., Lawrence, J.B., and Chess, A. (2007). A screen for nuclear transcripts identifies two linked noncoding RNAs associated with SC35 splicing domains. BMC Genomics 8, 39.

Iyer, M.K., Niknafs, Y.S., Malik, R., Singhal, U., Sahu, A., Hosono, Y., Barrette, T.R., Prensner, J.R., Evans, J.R., Zhao, S., et al. (2015). The landscape of long noncoding RNAs in the human transcriptome. Nat. Genet. 47, 199-208. 
Kent, W.J., Sugnet, C.W., Furey, T.S., Roskin, K.M., Pringle, T.H., Zahler, A.M., and Haussler, D. (2002). The human genome browser at UCSC. Genome Res. 12, 996-1006.

Khurana, E., Fu, Y., Chakravarty, D., Demichelis, F., Rubin, M.A., and Gerstein, M. (2016). Role of non-coding sequence variants in cancer (Nature Publishing Group).

Kim, K., K, J., W, Y., EY, C., SM, P., M, B., YJ, K., and JK, C. (2016). Chromatin structurebased prediction of recurrent noncoding mutations in cancer. Nat. Genet. 48, 1321-1326.

Kumar, S., Warrell, J., Li, S., McGillivray, P.D., Meyerson, W., Salichos, L., Harmanci, A., Martinez-Fundichely, A., Chan, C.W.Y., Nielsen, M.M., et al. (2020). Passenger Mutations in More Than 2,500 Cancer Genomes: Overall Molecular Functional Impact and Consequences. Cell 180, 915-927.e16.

Kunde, S.A., Musante, L., Grimme, A., Fischer, U., Müller, E., Wanker, E.E., and Kalscheuer, V.M. (2011). The X-chromosome-linked intellectual disability protein PQBP1 is a component of neuronal RNA granules and regulates the appearance of stress granules. Hum. Mol. Genet. 20, 4916-4931.

Lanzós, A., Carlevaro-Fita, J., Palumbo, E., Reverter, F., Mularoni, L., Guigó, R., Johnson, R., Reverter, F., Palumbo, E., Guigó, R., et al. (2017a). Discovery of Cancer Driver Long Noncoding RNAs across 1112 Tumour Genomes: New Candidates and Distinguishing Features. Sci. Rep. 7, 41544.

Lanzós, A., Carlevaro-Fita, J., Mularoni, L., Reverter, F., Palumbo, E., Guigó, R., and Johnson, R. (2017b). Discovery of Cancer Driver Long Noncoding RNAs across 1112 Tumour Genomes: New Candidates and Distinguishing Features. Sci. Rep. 7, 41544.

Lawrence, M.S., Stojanov, P., Polak, P., Kryukov, G. V., Cibulskis, K., Sivachenko, A., Carter, S.L., Stewart, C., Mermel, C.H., Roberts, S.A., et al. (2013). Mutational heterogeneity in cancer and the search for new cancer-associated genes. Nature 499, 214-218.

Leucci, E., Vendramin, R., Spinazzi, M., Laurette, P., Fiers, M., Wouters, J., Radaelli, E., Eyckerman, S., Leonelli, C., Vanderheyden, K., et al. (2016). Melanoma addiction to the long non-coding RNA SAMMSON. Nature 531, 518-522.

Li, K., Y, Z., X, L., Y, L., Z, G., H, C., KE, D., M, C., W, C., Z, S., et al. (2020). Noncoding Variants Connect Enhancer Dysregulation with Nuclear Receptor Signaling in Hematopoietic Malignancies. Cancer Discov. 10, 724-745. 
Li, X., Wang, X., Song, W., Xu, H., Huang, R., Wang, Y., Zhao, W., Xiao, Z., and Yang, X. (2018a). Oncogenic Properties of NEAT1 in Prostate Cancer Cells Depend on the CDC5LAGRN Transcriptional Regulation Circuit. Cancer Res. 78, 4138-4149.

Li, Y., Li, L., Wang, Z., Pan, T., Sahni, N., Jin, X., Wang, G., Li, J., Zheng, X., Zhang, Y., et al. (2018b). LncMAP: Pan-cancer atlas of long noncoding RNA-mediated transcriptional network perturbations. Nucleic Acids Res. 46, 1113-1123.

Liu, E.M., Martinez-Fundichely, A., Diaz, B.J., Apostolou, E., Sanjana, N.E., and Khurana Correspondence, E. (2019). Identification of Cancer Drivers at CTCF Insulators in 1,962 Whole Genomes.

Liu, S.J., Horlbeck, M.A., Cho, S.W., Birk, H.S., Malatesta, M., He, D., Attenello, F.J., Villalta, J.E., Cho, M.Y., Chen, Y., et al. (2017). CRISPRi-based genome-scale identification of functional long non-coding RNA loci in human cells. Science (80-. ). 06, 1-19.

MacLeod, A.R., and Crooke, S.T. (2017). RNA Therapeutics in Oncology: Advances, Challenges, and Future Directions. J. Clin. Pharmacol. 57, S43-S59.

Mao, Y.S., Sunwoo, H., Zhang, B., and Spector, D.L. (2011). Direct visualization of the cotranscriptional assembly of a nuclear body by noncoding RNAs. Nat. Cell Biol. 13, 95-101.

McCluggage, F., and Fox, A. (2021). Paraspeckle nuclear condensates: Global sensors of cell stress? Bioessays 43.

Melton, C., Reuter, J.A., Spacek, D. V, and Snyder, M. (2015). Recurrent somatic mutations in regulatory regions of human cancer genomes. Nat. Publ. Gr. 47.

Miladi, M., Raden, M., Diederichs, S., and Backofen, R. (2020). MutaRNA: analysis and visualization of mutation-induced changes in RNA structure. Nucleic Acids Res. 48, W287W291.

Miura, H., Quadros, R.M., Gurumurthy, C.B., and Ohtsuka, M. (2017). Easi-CRISPR for creating knock-in and conditional knockout mouse models using long ssDNA donors. Nat. Protoc. 2017131 13, 195-215.

Miura, K., Miura, S., Yamasaki, K., Shimada, T., Kinoshita, A., Niikawa, N., Yoshiura, K., and Masuzaki, H. (2010). The possibility of microarray-based analysis using cell-free placental mRNA in maternal plasma. Prenat. Diagn. 30, 849-861. 
Mularoni, L., Sabarinathan, R., Deu-Pons, J., Gonzalez-Perez, A., and López-Bigas, N. (2016). OncodriveFML: A general framework to identify coding and non-coding regions with cancer driver mutations. Genome Biol. 17, 128.

Nakagawa, S., Naganuma, T., Shioi, G., and Hirose, T. (2011). Paraspeckles are subpopulation-specific nuclear bodies that are not essential in mice. J. Cell Biol. 193, 31-39.

Naveed, A., JA, C., R, L., A, H., J, C., T, L., SD, W., S, F., and AH, F. (2021). NEAT1 polyAmodulating antisense oligonucleotides reveal opposing functions for both long non-coding RNA isoforms in neuroblastoma. Cell. Mol. Life Sci. 78, 2213-2230.

Nik-Zainal, S., Davies, H., Staaf, J., Ramakrishna, M., Glodzik, D., Zou, X., Martincorena, I., Alexandrov, L.B., Martin, S., Wedge, D.C., et al. (2016). Landscape of somatic mutations in 560 breast cancer whole-genome sequences. Nature 534, 47-54.

Ning, S., Zhang, J., Wang, P., Zhi, H., Wang, J., Liu, Y., Gao, Y., Guo, M., Yue, M., Wang, L., et al. (2016). Lnc2Cancer: a manually curated database of experimentally supported IncRNAs associated with various human cancers. Nucleic Acids Res. 44, D980-D985.

Nowell, P.C. (1976). The clonal evolution of tumor cell populations. Science 194, 23-28.

Paraskevopoulou, M.D., Vlachos, I.S., Karagkouni, D., Georgakilas, G., Kanellos, I., Vergoulis, T., Zagganas, K., Tsanakas, P., Floros, E., Dalamagas, T., et al. (2015). DIANA-LncBase v2: indexing microRNA targets on non-coding transcripts. Nucleic Acids Res. 44, D231-D238.

Paz, I., Kosti, I., Ares, M., Cline, M., and Mandel-Gutfreund, Y. (2014). RBPmap: a web server for mapping binding sites of RNA-binding proteins. Nucleic Acids Res. 42, W361-W367.

Priestley, P., Baber, J., Lolkema, M.P., Steeghs, N., de Bruijn, E., Shale, C., Duyvesteyn, K., Haidari, S., van Hoeck, A., Onstenk, W., et al. (2019). Pan-cancer whole-genome analyses of metastatic solid tumours. Nature 575, 210-216.

Puente, X., Beà, S., Valdés-Mas, R., Villamor, Gutiérrez-Abril, Martín-Subero, Munar, RubioPérez, R., P, J., Aymerich, et al. (2015). Non-coding recurrent mutations in chronic lymphocytic leukaemia. Nature 526, 519-524.

Quinlan, A.R., and Hall, I.M. (2010). BEDTools: a flexible suite of utilities for comparing genomic features. Bioinformatics 26, 841-842.

Redis, R.S., Vela, L.E., Lu, W., Ambrosio, A.L.B., Gomes Dias, S.M., and Calin, G.A. (2016). Allele-Specific Reprogramming of Cancer Metabolism by the Long Non-coding RNA CCAT2. 
Rentzsch, P., Witten, D., Cooper, G.M., Shendure, J., and Kircher, M. (2019). CADD: predicting the deleteriousness of variants throughout the human genome. Nucleic Acids Res. 47.

Rentzsch, P., Schubach, M., Shendure, J., and Kircher, M. (2021). CADD-Splice-improving genome-wide variant effect prediction using deep learning-derived splice scores. Genome Med. 13.

Rheinbay, E., Nielsen, M.M., Abascal, F., Tiao, G., Hornshøj, H., Hess, J.M., Pedersen, R.I.I., Feuerbach, L., Sabarinathan, R., Madsen, H.T., et al. (2017). Discovery and characterization of coding and non-coding driver mutations in more than 2,500 whole cancer genomes. BioRxiv 237313.

Rheinbay, E., Nielsen, M.M., Abascal, F., Wala, J.A., Shapira, O., Tiao, G., Hornshøj, H., Hess, J.M., Juul, R.I., Lin, Z., et al. (2020). Analyses of non-coding somatic drivers in 2,658 cancer whole genomes. Nature 578, 102-111.

Rubio-Perez, C., Tamborero, D., Schroeder, M.P., Antolín, A.A., Deu-Pons, J., Perez-Llamas, C., Mestres, J., Gonzalez-Perez, A., and Lopez-Bigas, N. (2015). In Silico Prescription of Anticancer Drugs to Cohorts of 28 Tumor Types Reveals Targeting Opportunities. Cancer Cell 27, 382-396.

Sabarinathan, R., Tafer, H., Seemann, S.E., Hofacker, I.L., Stadler, P.F., and Gorodkin, J. (2013). RNAsnp: Efficient Detection of Local RNA Secondary Structure Changes Induced by SNPs. Hum. Mutat. 34, 546-556.

Sanson, K.R., Hanna, R.E., Hegde, M., Donovan, K.F., Strand, C., Sullender, M.E., Vaimberg, E.W., Goodale, A., Root, D.E., Piccioni, F., et al. (2018). Optimized libraries for CRISPR-Cas9 genetic screens with multiple modalities. Nat. Commun. 9, 5416.

Sanz, L.A., Hartono, S.R., Lim, Y.W., Steyaert, S., Rajpurkar, A., Ginno, P.A., Xu, X., and Chédin, F. (2016). Prevalent, Dynamic, and Conserved R-Loop Structures Associate with Specific Epigenomic Signatures in Mammals. Mol. Cell 63, 167-178.

Sasaki, Y.T.F., Ideue, T., Sano, M., Mituyama, T., and Hirose, T. (2009). MEN / noncoding RNAs are essential for structural integrity of nuclear paraspeckles. Proc. Natl. Acad. Sci. 106, 2525-2530. 
Seemann, S.E., Mirza, A.H., Hansen, C., Bang-Berthelsen, C.H., Garde, C., ChristensenDalsgaard, M., Torarinsson, E., Yao, Z., Workman, C.T., Pociot, F., et al. (2017). The identification and functional annotation of RNA structures conserved in vertebrates. Genome Res. 27, 1371-1383.

Sentürk Cetin, N., Kuo, C.-C., Ribarska, T., Li, R., Costa, I.G., and Grummt, I. (2019). Isolation and genome-wide characterization of cellular DNA:RNA triplex structures. Nucleic Acids Res. 47, 2306-2321.

Shuai, S., Suzuki, H., Diaz-Navarro, A., Nadeu, F., Kumar, S.A., Gutierrez-Fernandez, A., Delgado, J., Pinyol, M., López-Otín, C., Puente, X.S., et al. (2019). The U1 spliceosomal RNA is recurrently mutated in multiple cancers. Nature $574,712-716$.

Siepel, A., Bejerano, G., Pedersen, J.S., Hinrichs, A.S., Hou, M., Rosenbloom, K., Clawson, H., Spieth, J., Hillier, L.W., Richards, S., et al. (2005). Evolutionarily conserved elements in vertebrate, insect, worm, and yeast genomes. Genome Res. 15, 1034-1050.

Simko, E.A.J., Liu, H., Zhang, T., Velasquez, A., Teli, S., Haeusler, A.R., and Wang, J. (2020). G-quadruplexes offer a conserved structural motif for NONO recruitment to NEAT1 architectural IncRNA. Nucleic Acids Res. 48, 7421-7438.

Sondka, Z., Bamford, S., Cole, C.G., Ward, S.A., Dunham, I., and Forbes, S.A. (2018). The COSMIC Cancer Gene Census: describing genetic dysfunction across all human cancers. Nat. Rev. Cancer 18, 696.

Spiniello, M., Knoener, R.A., Steinbrink, M.I., Yang, B., Cesnik, A.J., Buxton, K.E., Scalf, M., Jarrard, D.F., and Smith, L.M. (2018). HyPR-MS for Multiplexed Discovery of MALAT1, NEAT1, and NORAD IncRNA Protein Interactomes. J Proteome Res 17, 3022-3038.

Stamatoyannopoulos, J.A., Adzhubei, I., Thurman, R.E., Kryukov, G. V, Mirkin, S.M., and Sunyaev, S.R. (2009). Human mutation rate associated with DNA replication timing. Nat. Genet. 2009414 41, 393-395.

Statello, L., CJ, G., LL, C., M, H., Statello, L., Guo, C.J., Chen, L.L., and Huarte, M. (2021). Gene regulation by long non-coding RNAs and its biological functions.

Szklarczyk, D., Gable, A.L., Lyon, D., Junge, A., Wyder, S., Huerta-Cepas, J., Simonovic, M., Doncheva, N.T., Morris, J.H., Bork, P., et al. (2019). STRING v11: protein-protein association networks with increased coverage, supporting functional discovery in genome-wide experimental datasets. Nucleic Acids Res. 47, D607-D613. 
Tokheim, C.J., Papadopoulis, N., Kinzler, K.W., Vogelstein, B., and Karchin, R. (2016). Evaluating the Evaluation of Cancer Driver Genes.

Tomasetti, C., Marchionni, L., Nowak, M.A., Parmigiani, G., and Vogelstein, B. (2015). Only three driver gene mutations are required for the development of lung and colorectal cancers. $112,118-123$.

Uhlen, M., Fagerberg, L., Hallstrom, B.M., Lindskog, C., Oksvold, P., Mardinoglu, A., Sivertsson, A., Kampf, C., Sjostedt, E., Asplund, A., et al. (2015). Tissue-based map of the human proteome. Science (80-. ). 347, 1260419.

Umer, H., Smolinska, K., Komorowski, J., and Wadelius, C. (2021). Functional annotation of noncoding mutations in cancer. Life Sci. Alliance 4.

Uszczynska-Ratajczak, B., Lagarde, J., Frankish, A., Guigó, R., and Johnson, R. (2018). Towards a complete map of the human long non-coding RNA transcriptome. Nat. Rev. Genet. 19, 535-548.

Vancura, A., A, L., N, B.-G., MT, E., AH, G., S, H., R, J., Vancura, A., Lanzós, A., BoschGuiteras, N., et al. (2021). Cancer LncRNA Census 2 (CLC2): an enhanced resource reveals clinical features of cancer IncRNAs. NAR Cancer 3.

Vinagre, J., Almeida, A., Pópulo, H., Batista, R., Lyra, J., Pinto, V., Coelho, R., Celestino, R., Prazeres, H., Lima, L., et al. (2013). Frequency of TERT promoter mutations in human cancers. Nat. Commun. 201341 4, 1-6.

Vogelstein, B., and Kinzler, K.W. (2015). The Path to Cancer - Three Strikes and You're Out. Http://Dx.Doi.Org/10.1056/NEJMp1508811 373, 1895-1898.

Wang, F., Zuroske, T., and Watts, J.K. (2020). RNA therapeutics on the rise.

Wang, J., Zhang, X., Chen, W., Li, J., and Liu, C. (2018). CRIncRNA: a manually curated database of cancer-related long non-coding RNAs with experimental proof of functions on clinicopathological and molecular features. BMC Med. Genomics 11.

Wang, L., Park, H.J., Dasari, S., Wang, S., Kocher, J.-P., and Li, W. (2013). CPAT: CodingPotential Assessment Tool using an alignment-free logistic regression model. Nucleic Acids Res. 41, e74. 
Wedge, D.C., Gundem, G., Mitchell, T., Woodcock, D.J., Martincorena, I., Ghori, M., Zamora, J., Butler, A., Whitaker, H., Kote-Jarai, Z., et al. (2018). Sequencing of prostate cancers identifies new cancer genes, routes of progression and drug targets. Nat. Genet. 201850550 , 682-692.

West, J.A., Davis, C.P., Sunwoo, H., Simon, M.D., Sadreyev, R.I., Wang, P.I., Tolstorukov, M.Y., and Kingston, R.E. (2014). The long noncoding RNAs NEAT1 and MALAT1 bind active chromatin sites. Mol. Cell 55, 791-802.

Yamazaki, T., Souquere, S., Chujo, T., Kobelke, S., Chong, Y.S., Fox, A.H., Bond, C.S., Nakagawa, S., Pierron, G., and Hirose, T. (2018). Functional Domains of NEAT1 Architectural IncRNA Induce Paraspeckle Assembly through Phase Separation. Mol Cell 70, 1038-1053 e7.

Yanai, I., Benjamin, H., Shmoish, M., Chalifa-Caspi, V., Shklar, M., Ophir, R., Bar-Even, A., Horn-Saban, S., Safran, M., Domany, E., et al. (2005). Genome-wide midrange transcription profiles reveal expression level relationships in human tissue specification. Bioinformatics 21 , 650-659.

Z, C., H, J., S, Y., T, Z., X, J., P, L., J, J., N, L., B, T., and Y, L. (2018). Prader-Willi region nonprotein coding RNA 1 suppressed gastric cancer growth as a competing endogenous RNA of miR-425-5p. Clin. Sci. (Lond). 132, 1003-1019.

Zhou, S., JR, H., F, S., G, G., M, T., SA, M.T., JT, H., KJ, K., P, M., M, A., et al. (2020). Noncoding mutations target cis-regulatory elements of the FOXA1 plexus in prostate cancer. Nat. Commun. 11.

Zhu, H., Uusküla-Reimand, L., Isaev, K., Wadi, L., Alizada, A., Shuai, S., Huang, V., AdulusoNwaobasi, D., Paczkowska, M., Abd-Rabbo, D., et al. (2020). Candidate Cancer Driver Mutations in Distal Regulatory Elements and Long-Range Chromatin Interaction Networks. 77, 1307-1321.e10. 
bioRxiv preprint doi: https://doi org/10.1101/2021.11.06.467555; this version posted January 11, 2022. The copyright holder for this preprint (which was not certified by peer review) is the author/funder, who has granted bioRxiv a license to display the preprint in Figure 1 perpetuity. It is made available under aCC-BY-NC-ND 4.0 International license.

A Whole genome somatic mutations
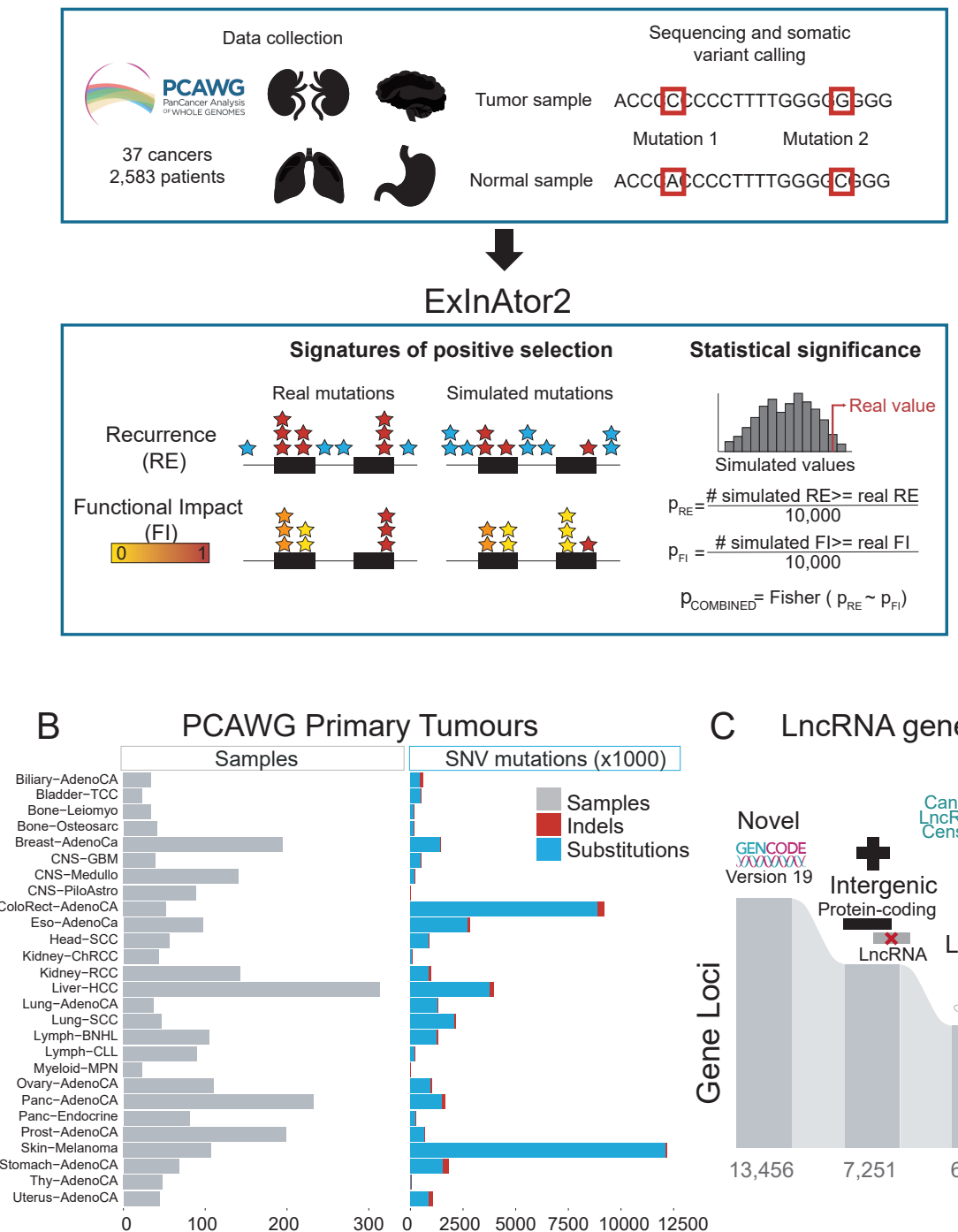

C LncRNA genes

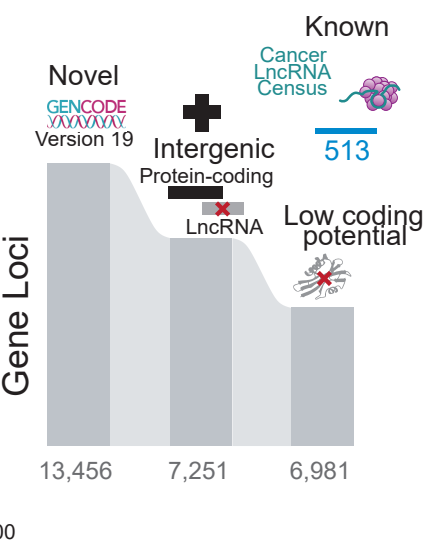


Figure 2 bioRxiv preprint doi: https://doi.org/10.1101/2021.11.06.467555; this version posted January 11, 2022. The copyright holder for this preprint (which was not certified by peer review) is the author/funder, who has granted bioRxiv a license to display the preprint in perpetuity. It is made available under aCC-BY-NC-ND 4.0 International license.

A Tested driver methods B Gene sets for benchmark E Driver predicions, IncRNA

Method
ExInAtor2
PCAWGc
compositeDrive
DriverPower
ncDriverCons
oncodriveFML
ActiveDriver
ExInAtor
LARVA
NBR
ncdDetect
Mutsig

$\mathrm{RE} / \mathrm{FI}$
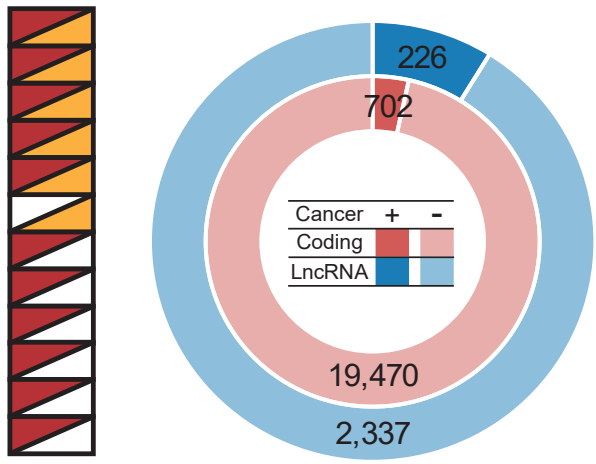

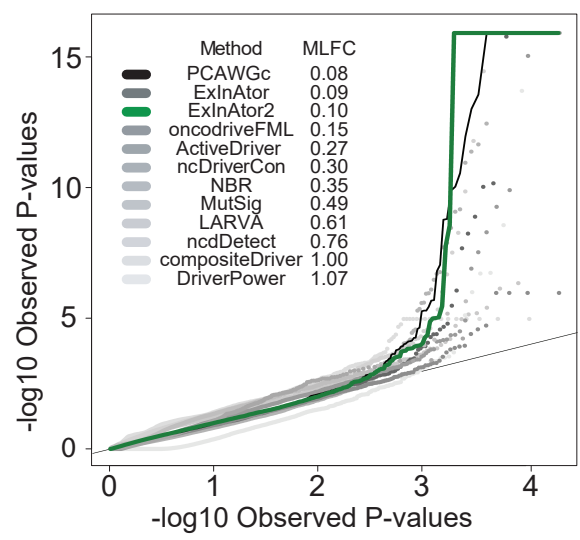

\section{Pancancer benchmark,IncRNA}

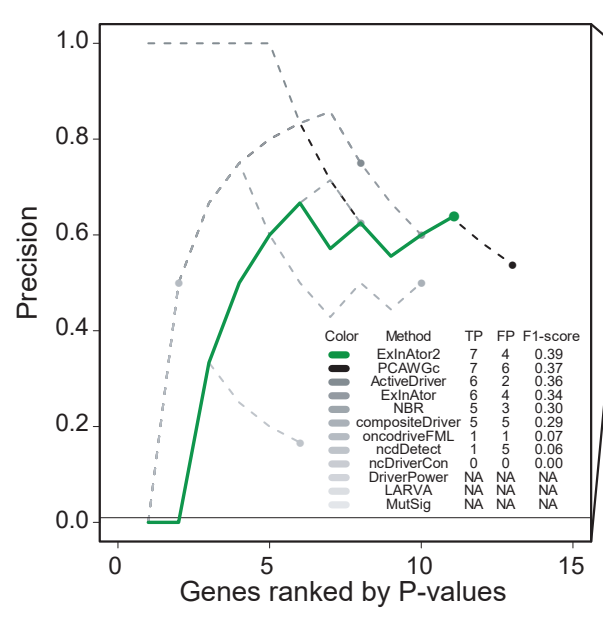

\section{Candidates}

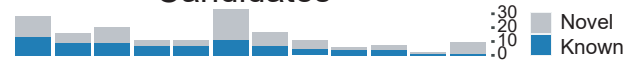

$(x+1)=1$

Pancan Bladder-TCC CNS-GBM CNS-PiduAstro
ColoRect-AdenoCA Eso-AdenoCA Kidney-ChRC Kidney-RCC Lung-AdenoCA
Lung-SCC Lymph-BNH Myeloid-MPN Ovary-AdenoCA
Panc-AdenoCA Panc-Endocrine
Prost-AdenoCA Prost-AdenoCA
Skin-Melanoma Genes ranked by P-values Uterus-AdenoCA

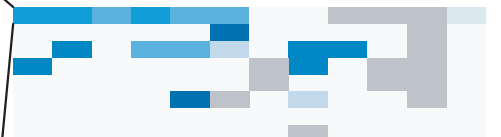
F1-score $\square$ NA 
bioRxiv preprint doi: https://doi.org/10.1101/2021.11.06.467555; this version posted January 11,2022 . The copyright holder for this Figurepkint (which was not certified by peer review) is the author/funder, who has granted bioRxiv a license to display the preprint in perpetuity. It is made available under ACC-BY-NC-ND 4.0 International license.

A Driver IncRNA oncoplot

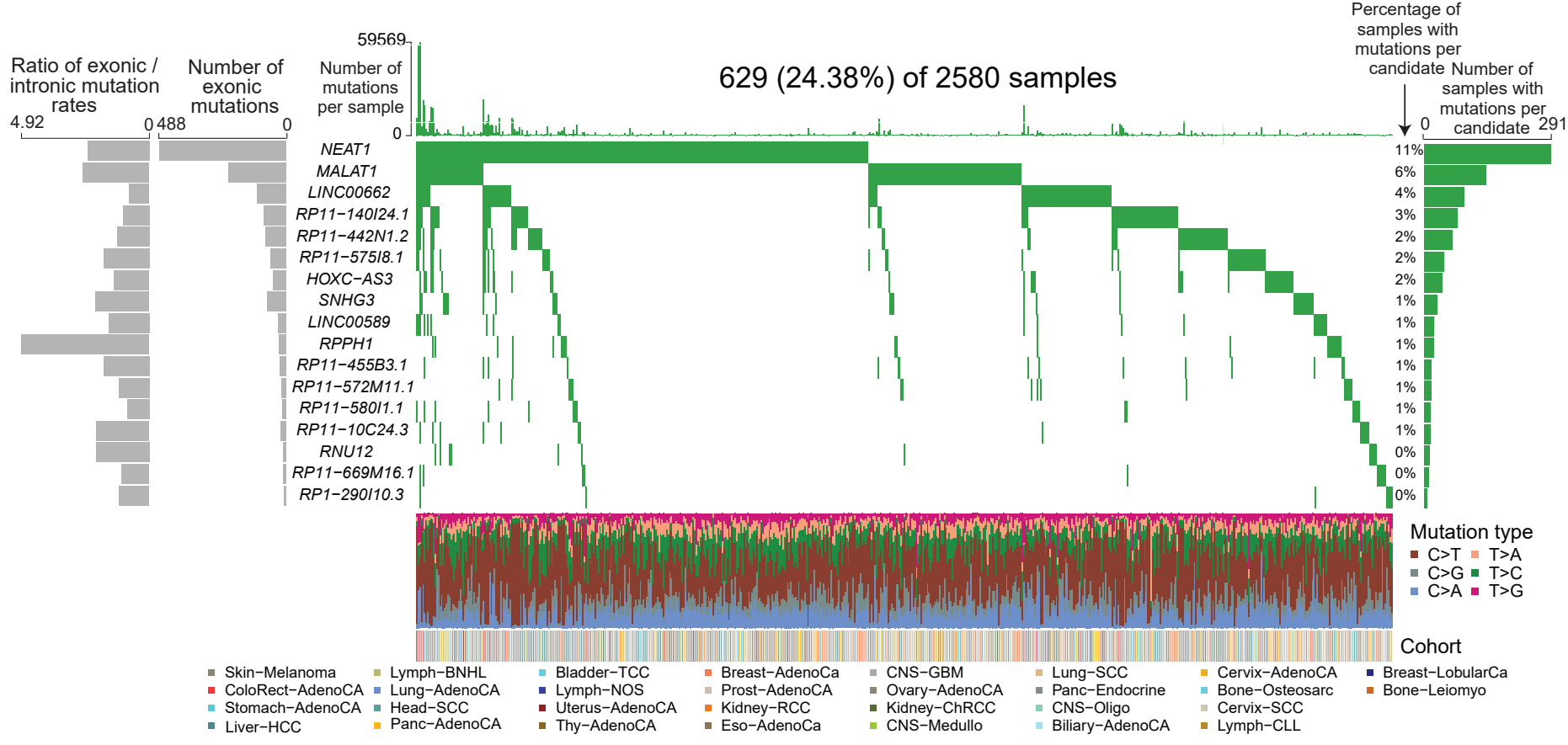

B LncRNA candidates across all cohorts

C Driver IncRNA overlap

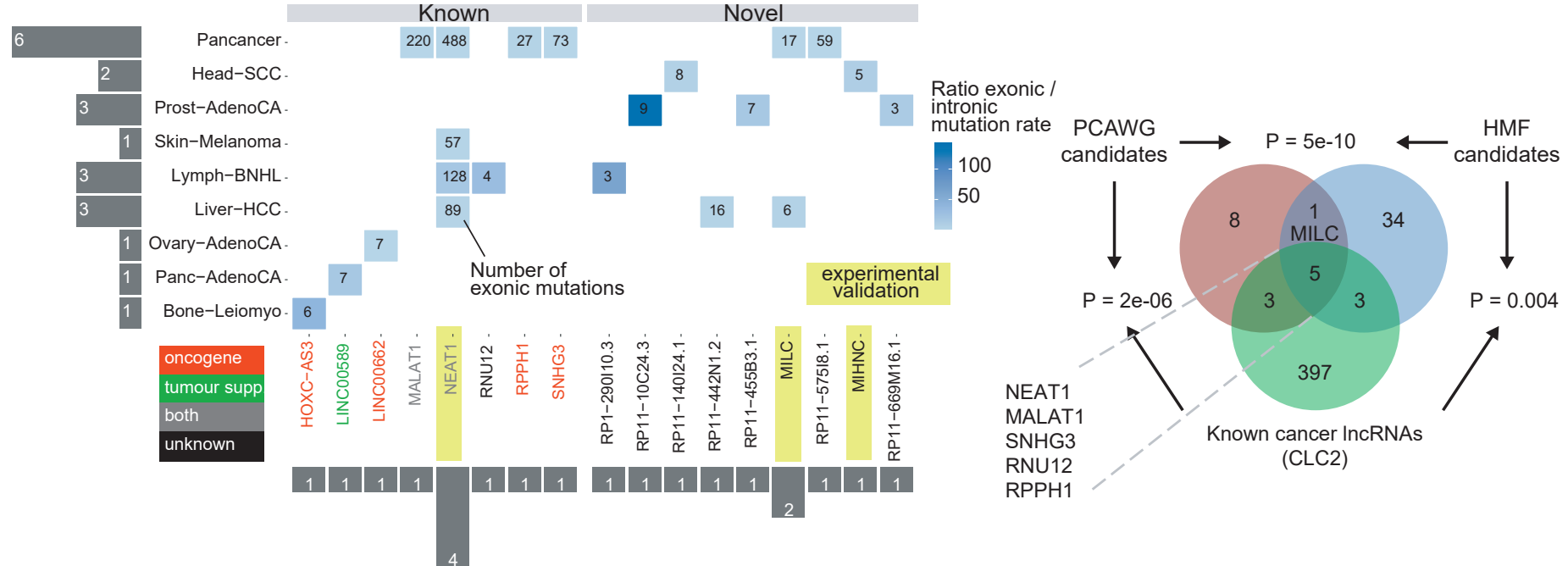

D Driver IncRNA genomic features
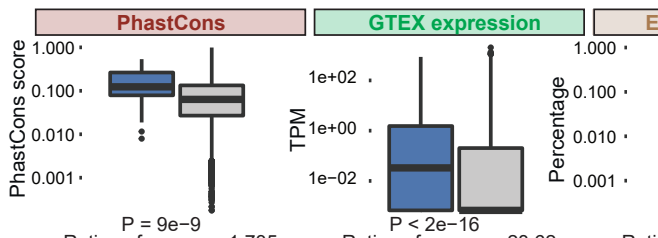

$\begin{aligned} P=9 e-9 & \\ \text { Ration of means } & =1.735\end{aligned}$

$\mathrm{P}<2 \mathrm{e}-16$
Ration of means $=28.62$

$\mathrm{P} \dot{\doteq} 0.38 \stackrel{\bullet}{*}$
Ration of means $=0.813$

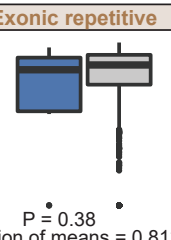

ECand ENon-Cand
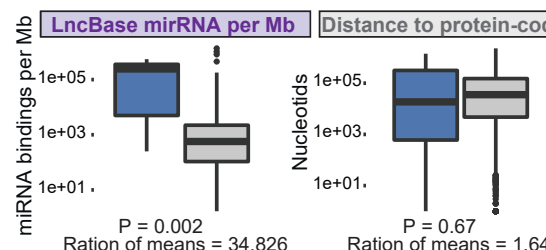

$P=0.67$
Ration of means $=1.644$

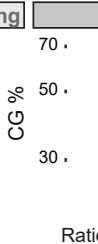

30.

$\begin{gathered}P=0.66 \\ \text { tion of means }\end{gathered}=0.993$

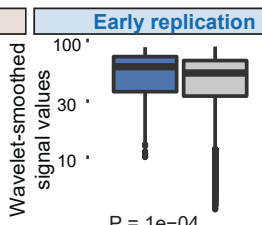

$P=1 e-04$
Ration of means $=1.097$
Exonic length

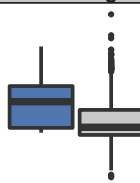

$\begin{gathered}P=6 \mathrm{e}-05 \\ \text { Ration of means }\end{gathered}=3.091$
E Driver IncRNA clinical features

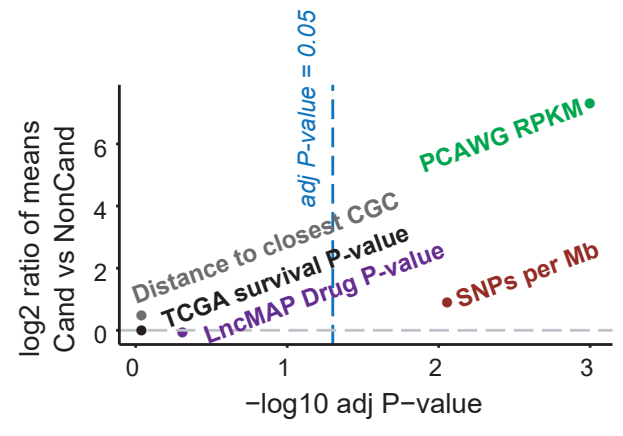


Figure 4 bioRxiv preprint doi: https://doi.org/10.1101/2021.11.06.467555; this version posted January 11, 2022. The copyright holder for this

A

B

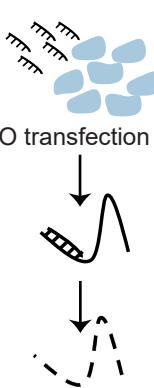
LnCRNA KD

\section{C} qRT-PCR, HuH7

Cell viability, HuH7
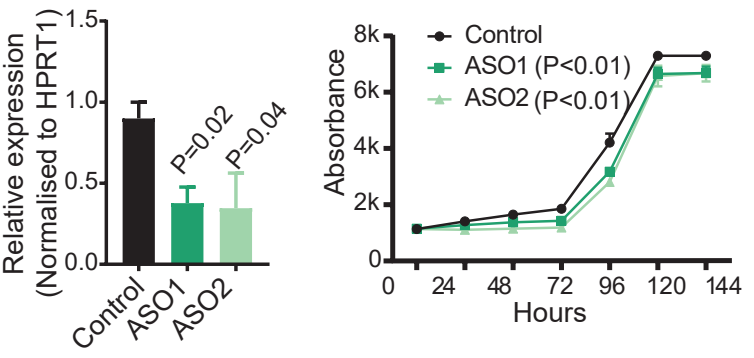

\section{G}

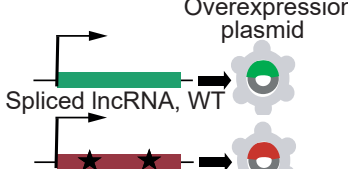

Spliced IncRNA, Mut

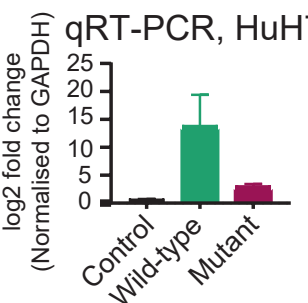

$\mathrm{H}$
MILC

Cell viability, $\mathrm{HuH} 7$

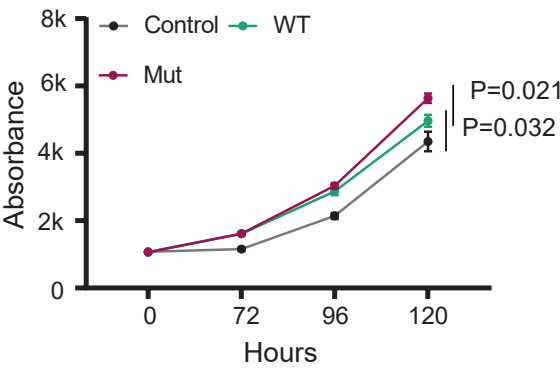

E

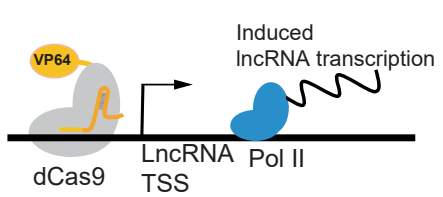

F Cell viability, HeLa

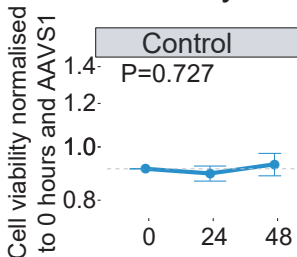

$\mathrm{K}$

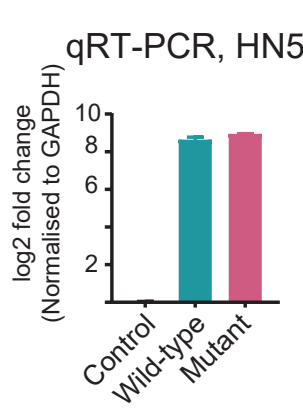

Expression fold change

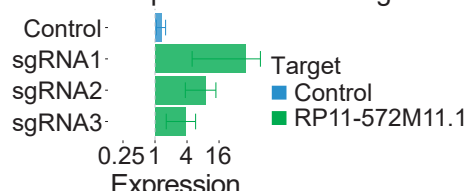

Expression

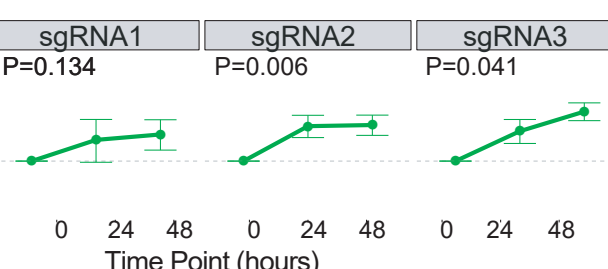

J Colony forming assay, HN5

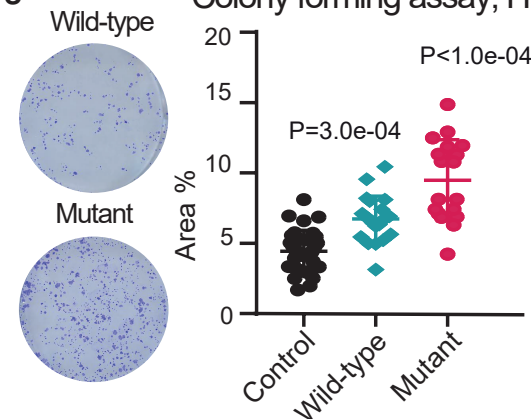

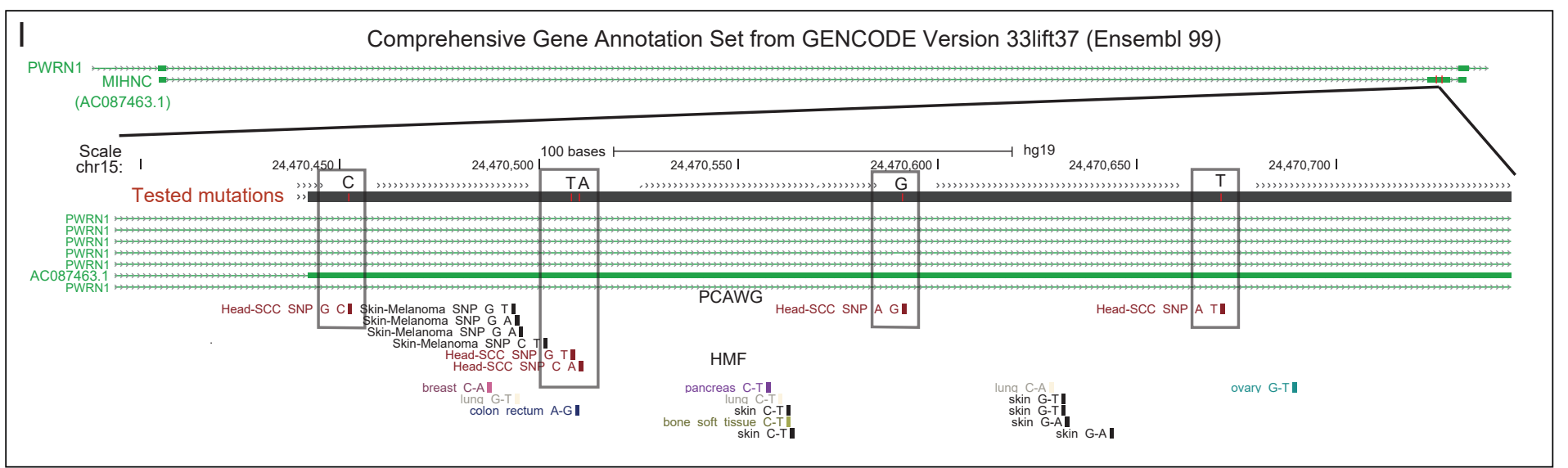


Figure 5

bioRxiv preprint doi: https://doi.org/10.1101/2021.11.06.467555; this version posted January 11, 2022. The copyright holder for this preprint (which was not certified by peer review) is the author/funder, who has granted bioRxiv a license to display the preprint in perpetuity. It is made avajiable under aCC-BY-NC-ND 4.0 International license.

A

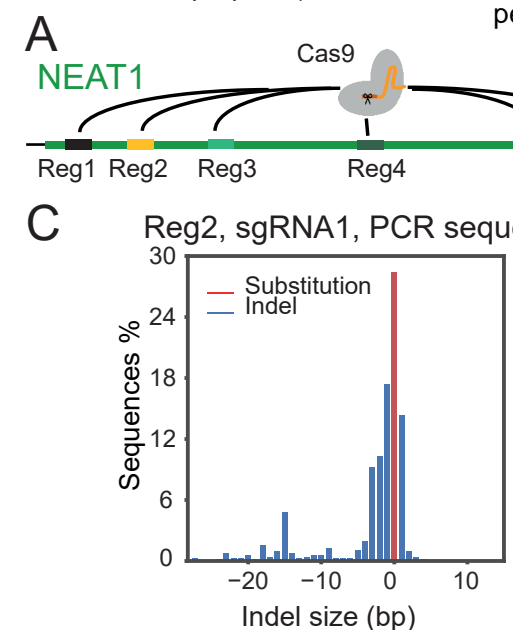

D Fitness competition assay

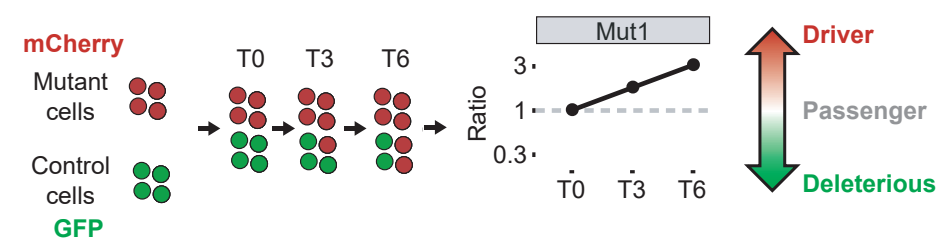

\section{cing}
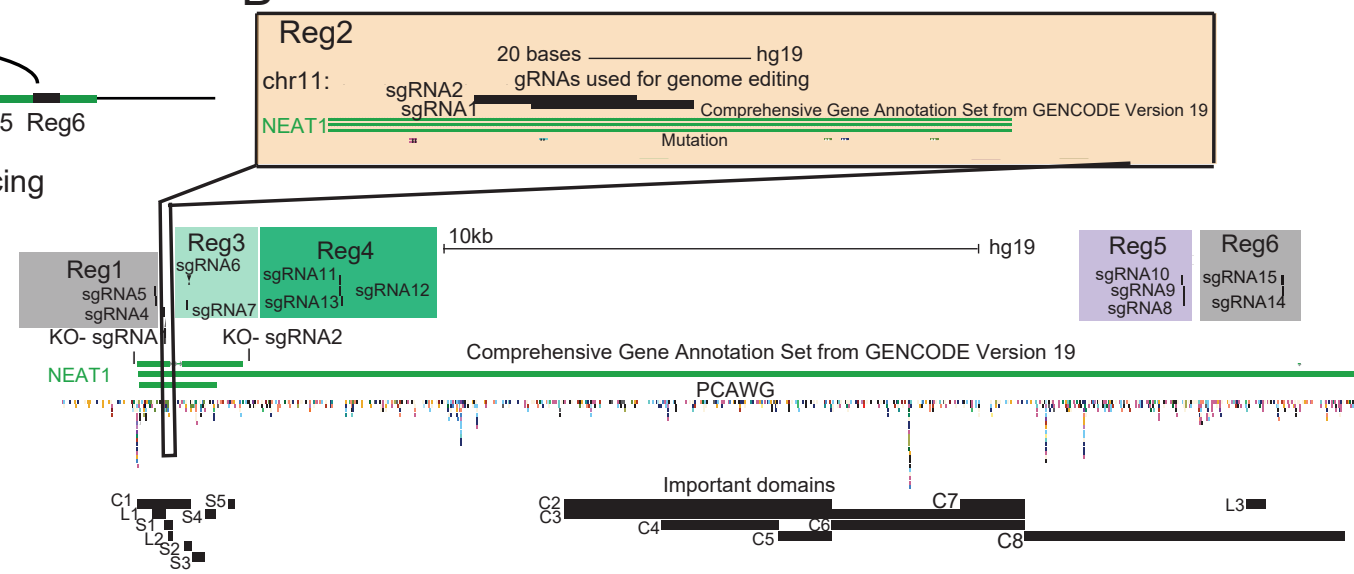

E Pooled competition assay
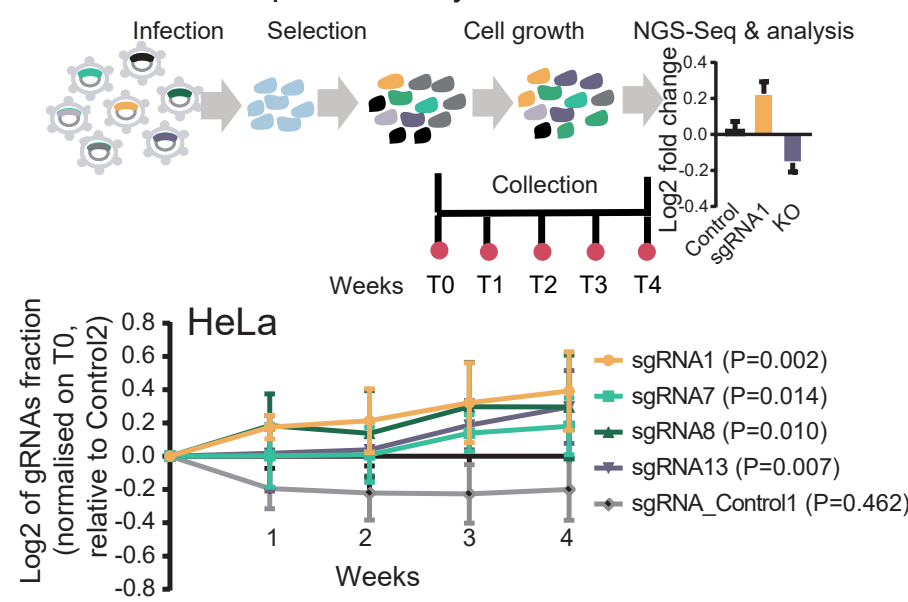

F Spheroids, HCT116
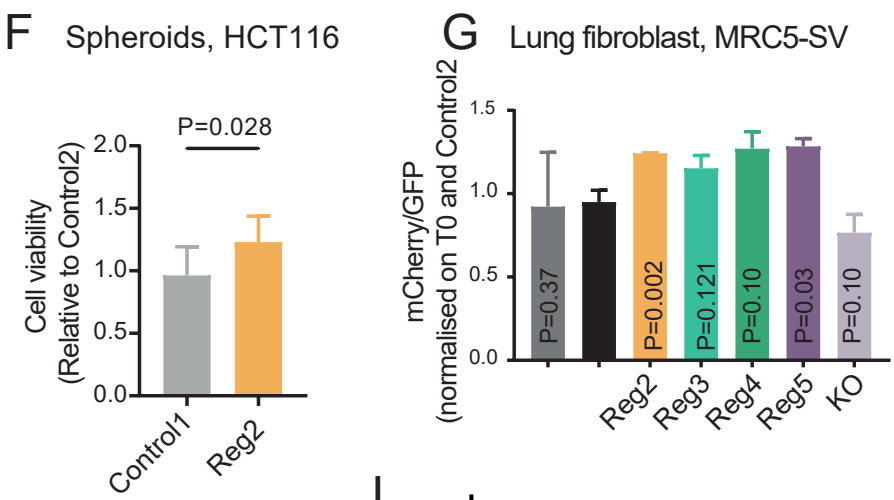

$\mathrm{H}$

Soft agar, MRC5-SV

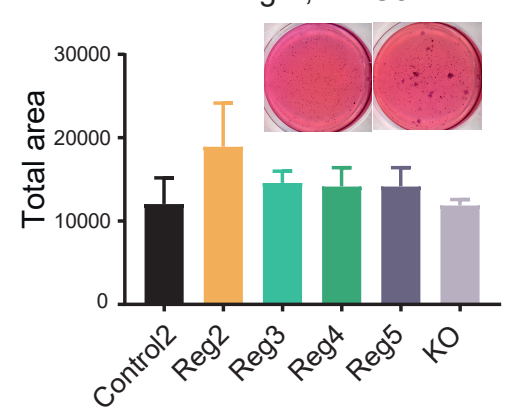

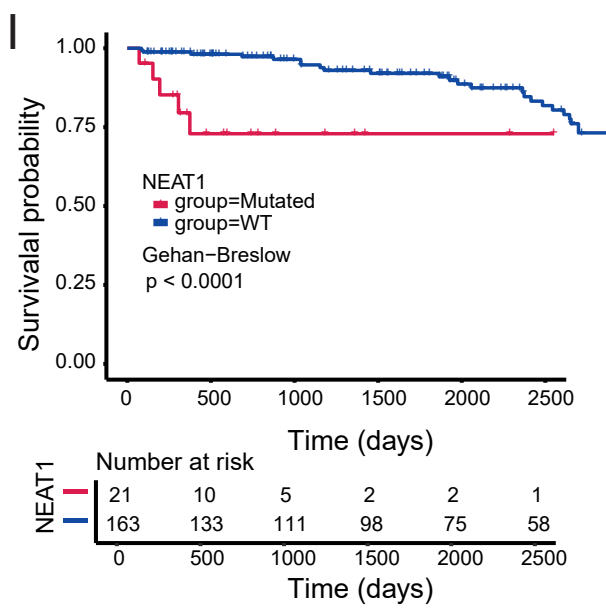


CioRxiv preprint doi: https://doi.org/10.1101/2021.11.06.467555; this version posted January $11,2022$. The copyright holder for this Figure $6 \begin{gathered}\text { bioRxiv preprint doi: https://doi.org/10.1101/2021.11.06.467555; this version posted January } 11,2022 \text {. The copyright holder for this } \\ \text { preprint (which was not certified by peer review) is the author/funder, who has granted bioRxiv a license to display the preprint in }\end{gathered}$ perpetuity. It is made available under aCC-BY-NC-ND 4.0 International license.

A Total NEAT1 expression, HeLA NEAT1_2 expression, HeLa

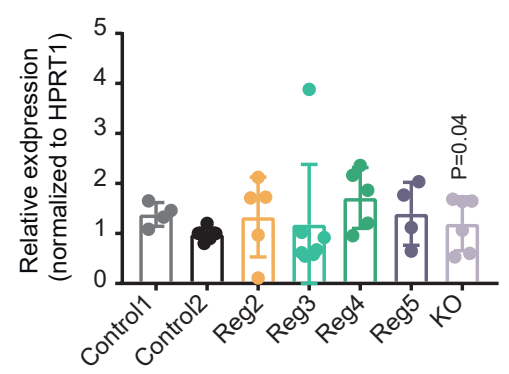

D Paraspeckle counts, HeLa

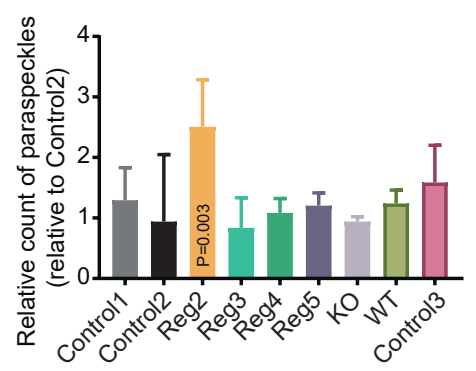

G

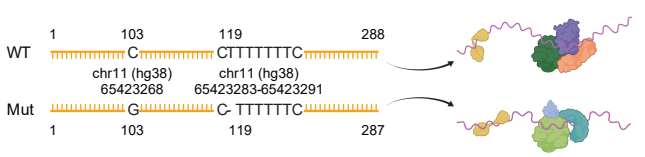

J STRING interaction etwork
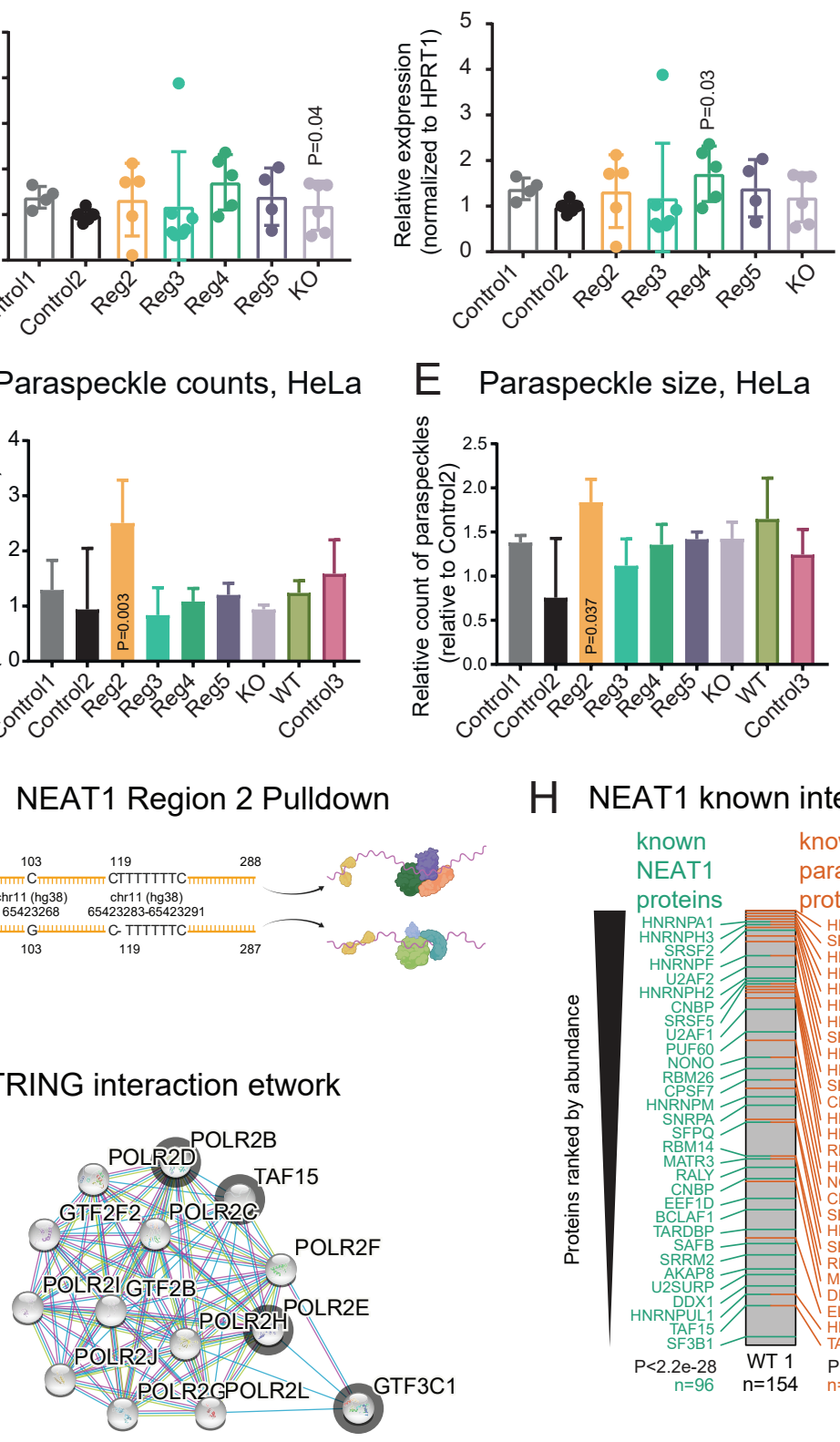

E Paraspeckle size, HeLa

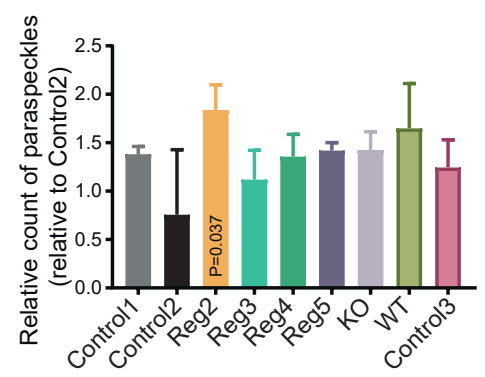

C Fluorescent In Situ Hybridization, HeLa

H NEAT1 known interactors

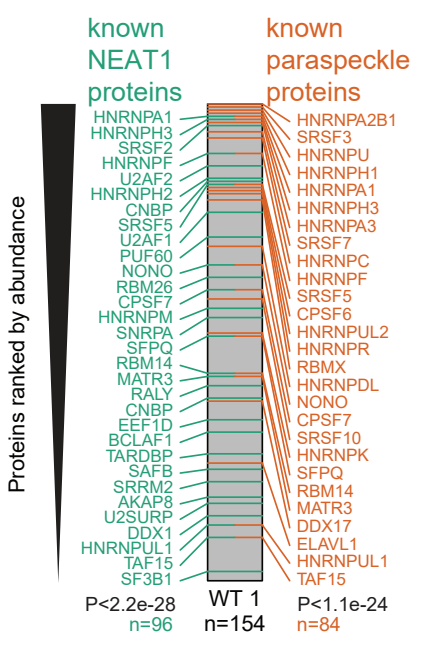

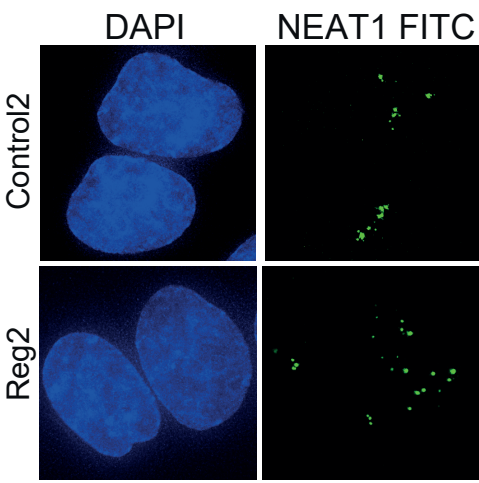

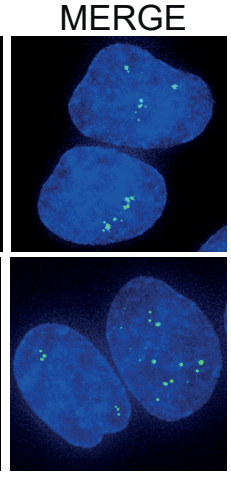

F Potential mechanism of IncRNA driver SNV

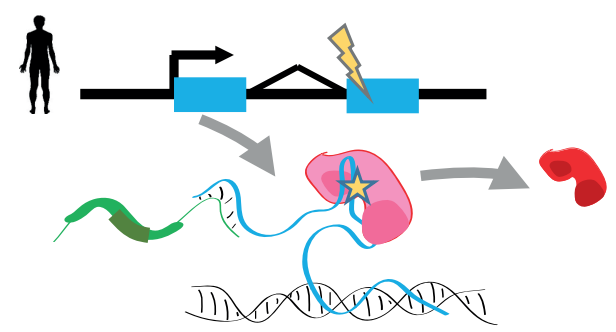

I Changing interactors

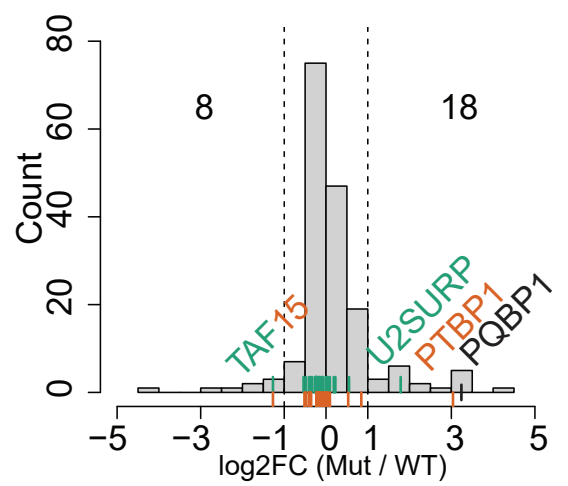


Supplementary Figure 1

A

ExInAtor2 - Mutational burden module

LncRNA

Nucleotide

Gene
Background (intron + surrounding)

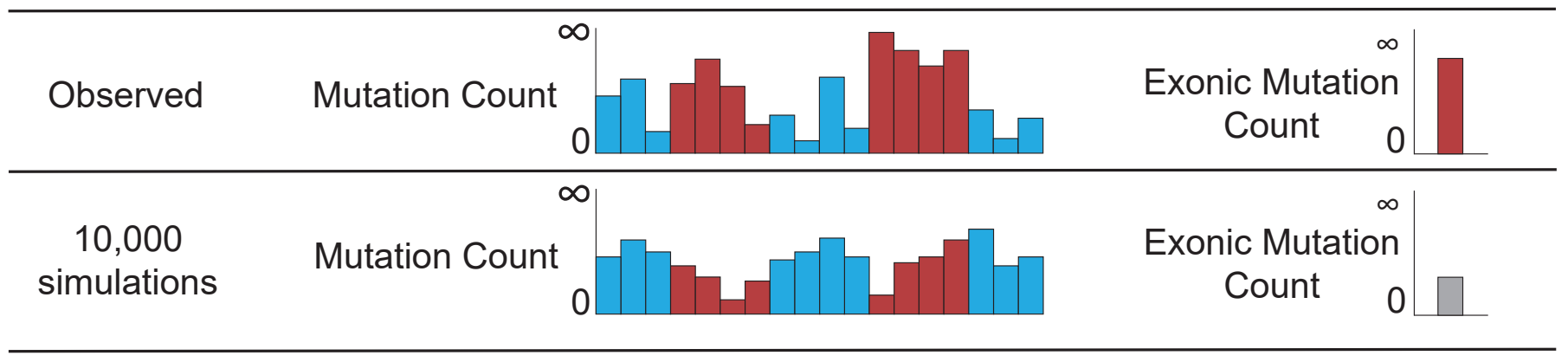

Significance

estimation

Frequency

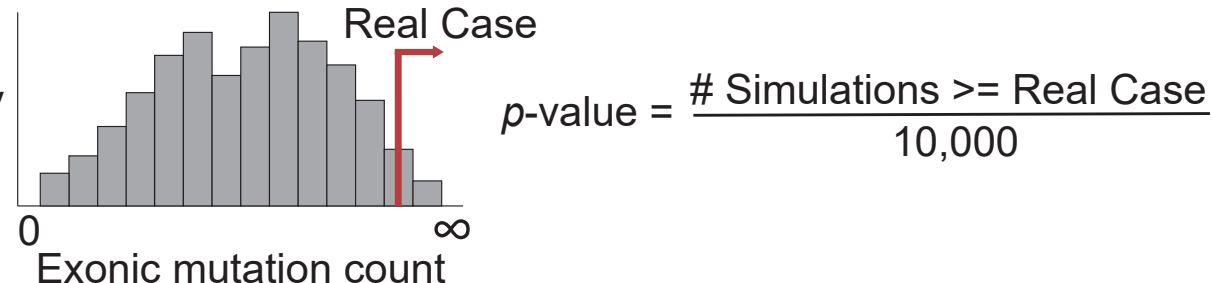

B

ExInAtor2 - Functional impact module

LncRNA

Exonic Nucleotide

Mutation

Wild Type

Gene

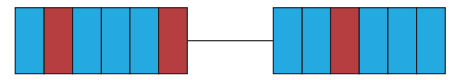

\begin{tabular}{ccc|c|c|}
\hline Observed & $\begin{array}{c}\text { Functional } \\
\text { Impact }\end{array}$ & & 1
\end{tabular}

Significance

estimation

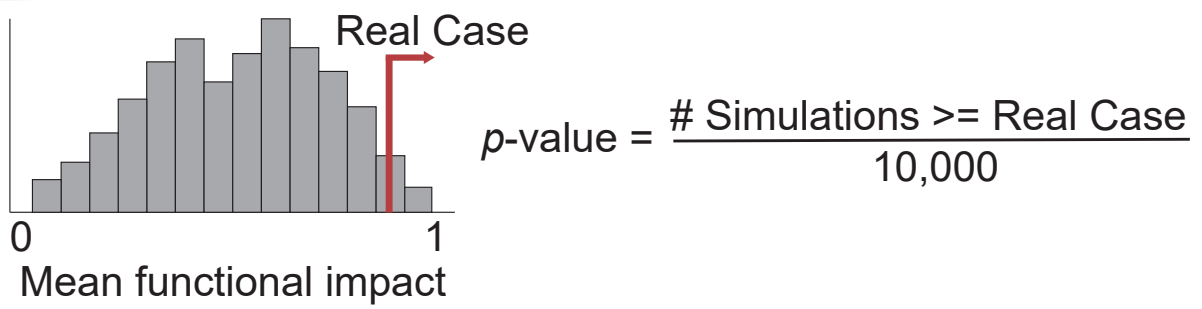


bioRxiv preprint doi: https://doi.org/10.1101/2021.11.06.467555; this version posted January 11, 2022. The copyright holder for this preprint (which was not certified by peer review) is the author/funder, who has granted bioRxiv a license to display the preprint in perpetuity. It is made available under aCC-BY-NC-ND 4.0 International license.

Supplementary Figure 2

A

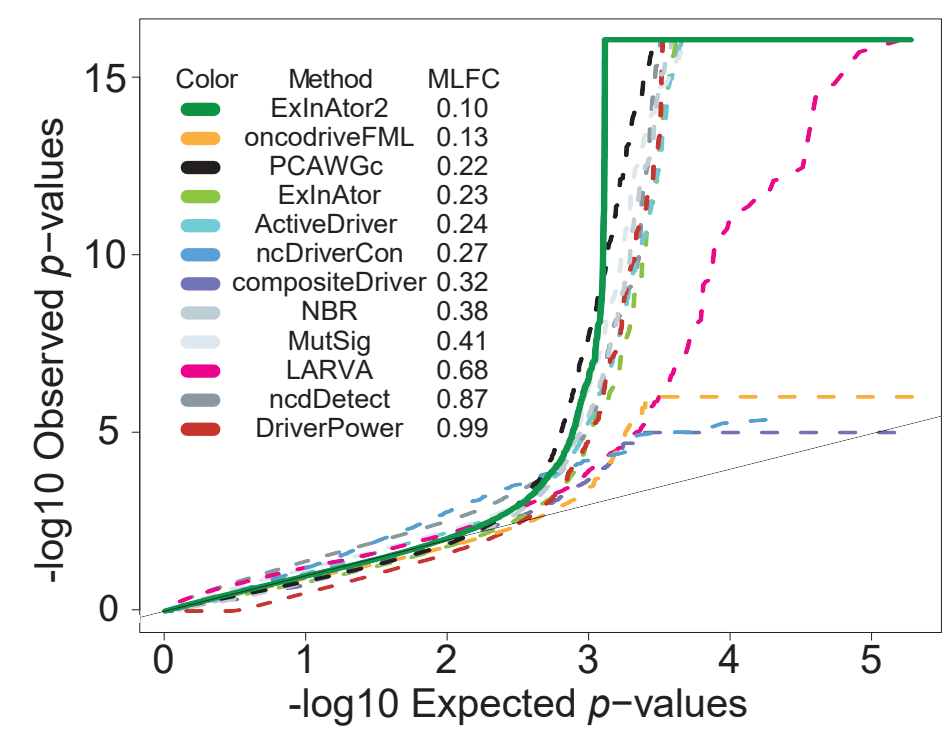

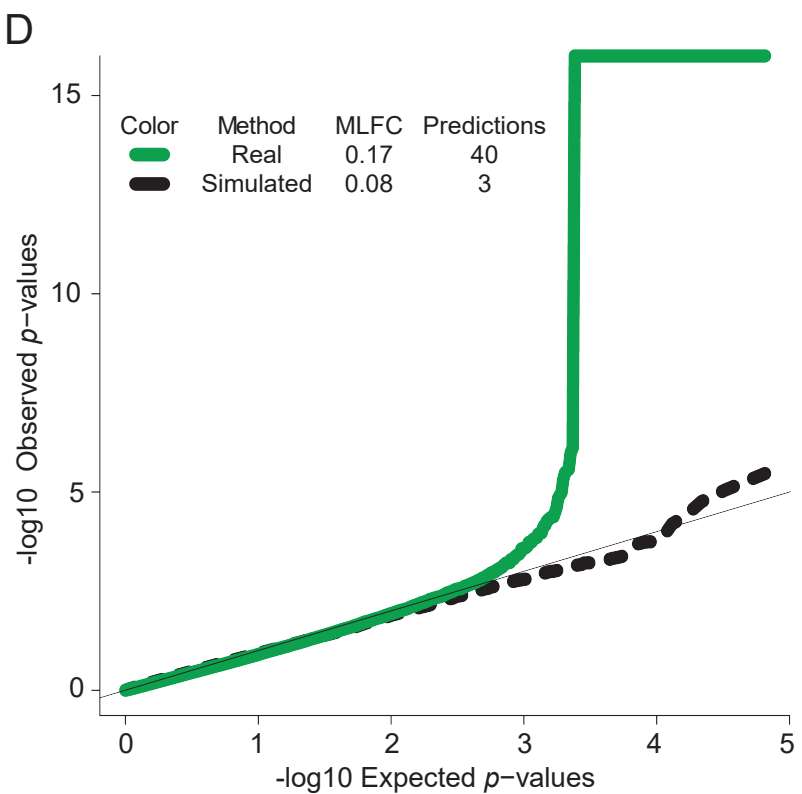

B

C

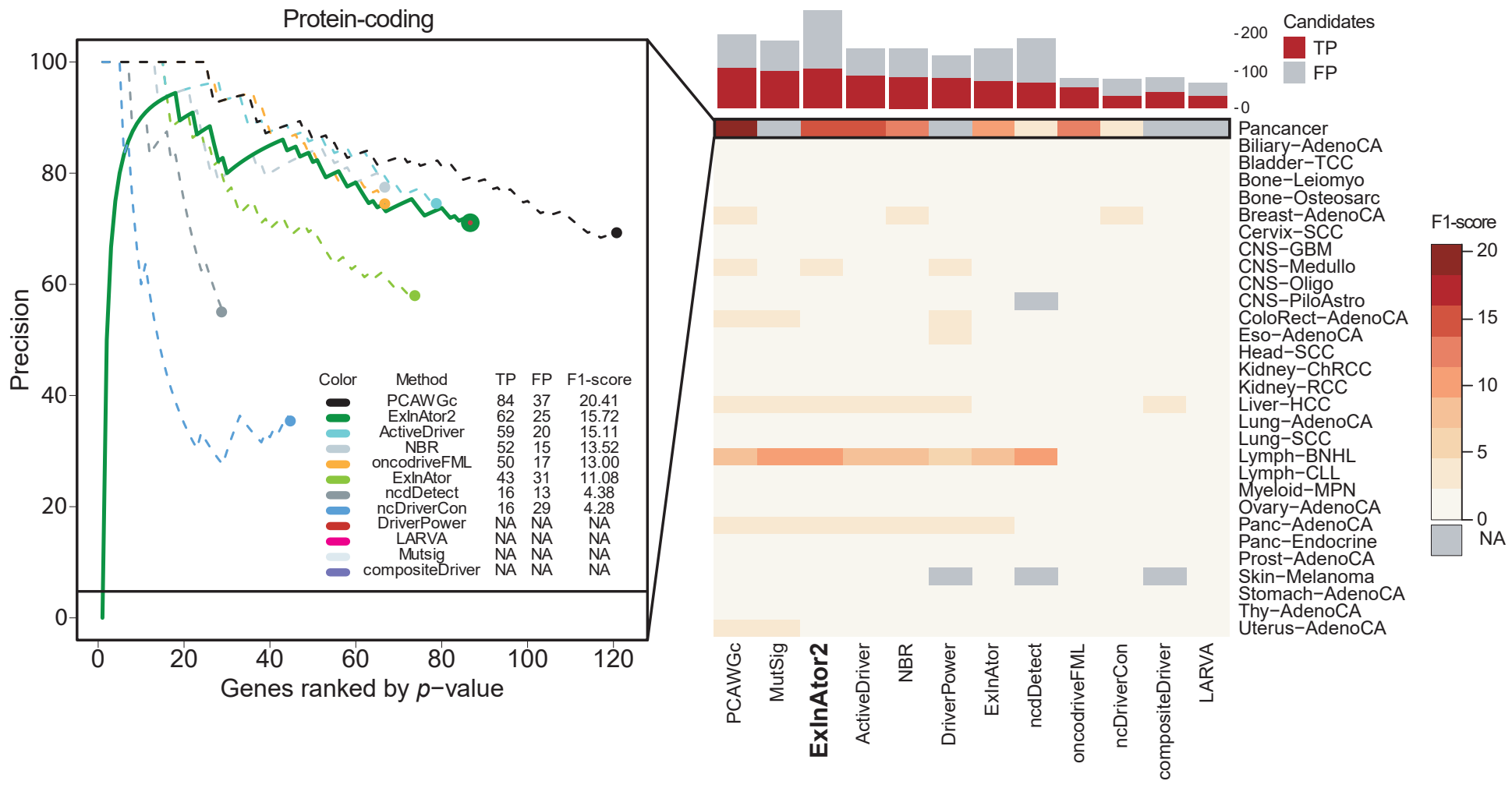


bioRxiv preprint doi: https://doi.org/10.1101/2021.11.06.467555; this version posted January 11, 2022. The copyright holder for this

preprint (which was not certified by peer review) is the author/funder, who has granted bioRxiv a license to display the preprint in

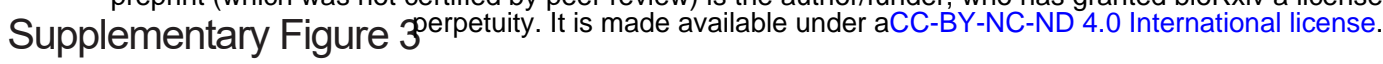

A

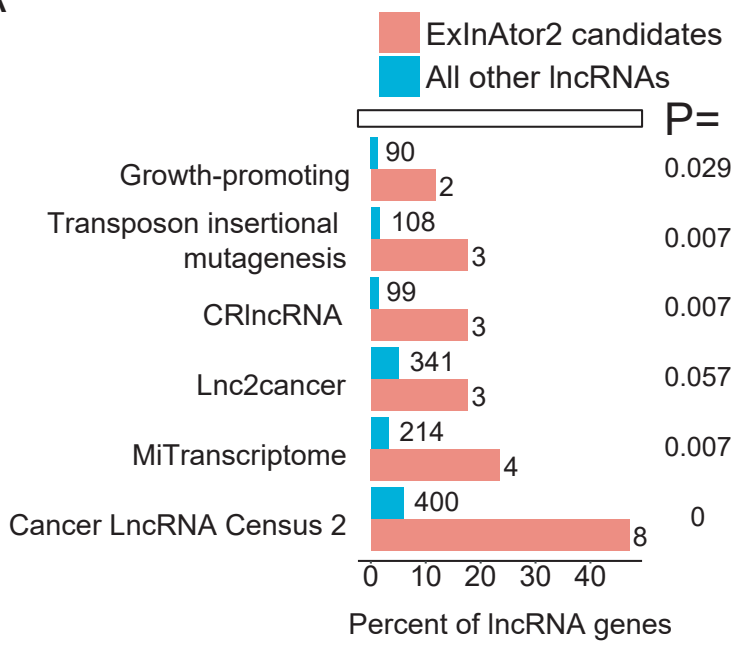

B

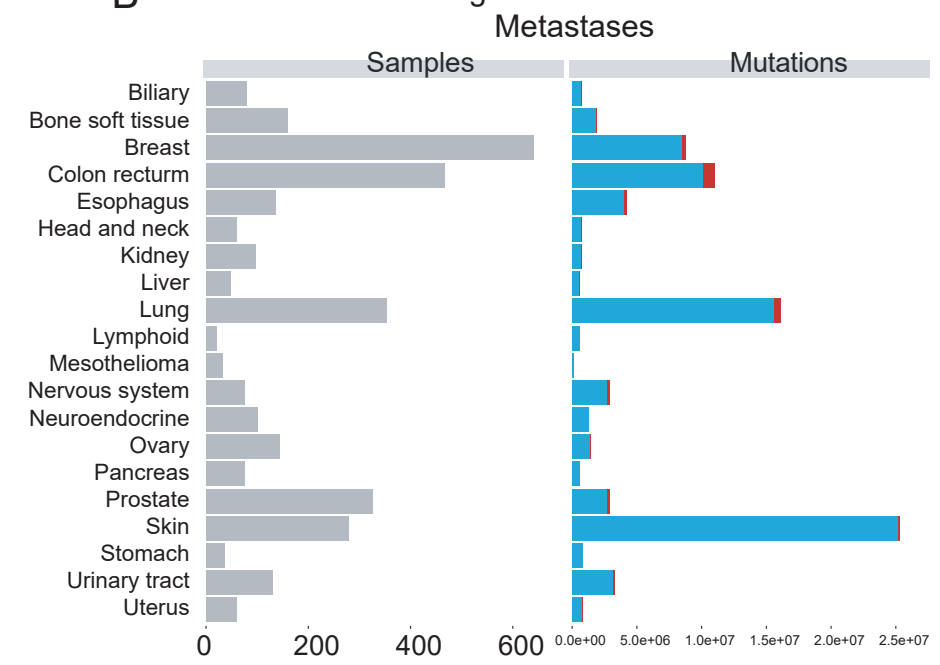

C

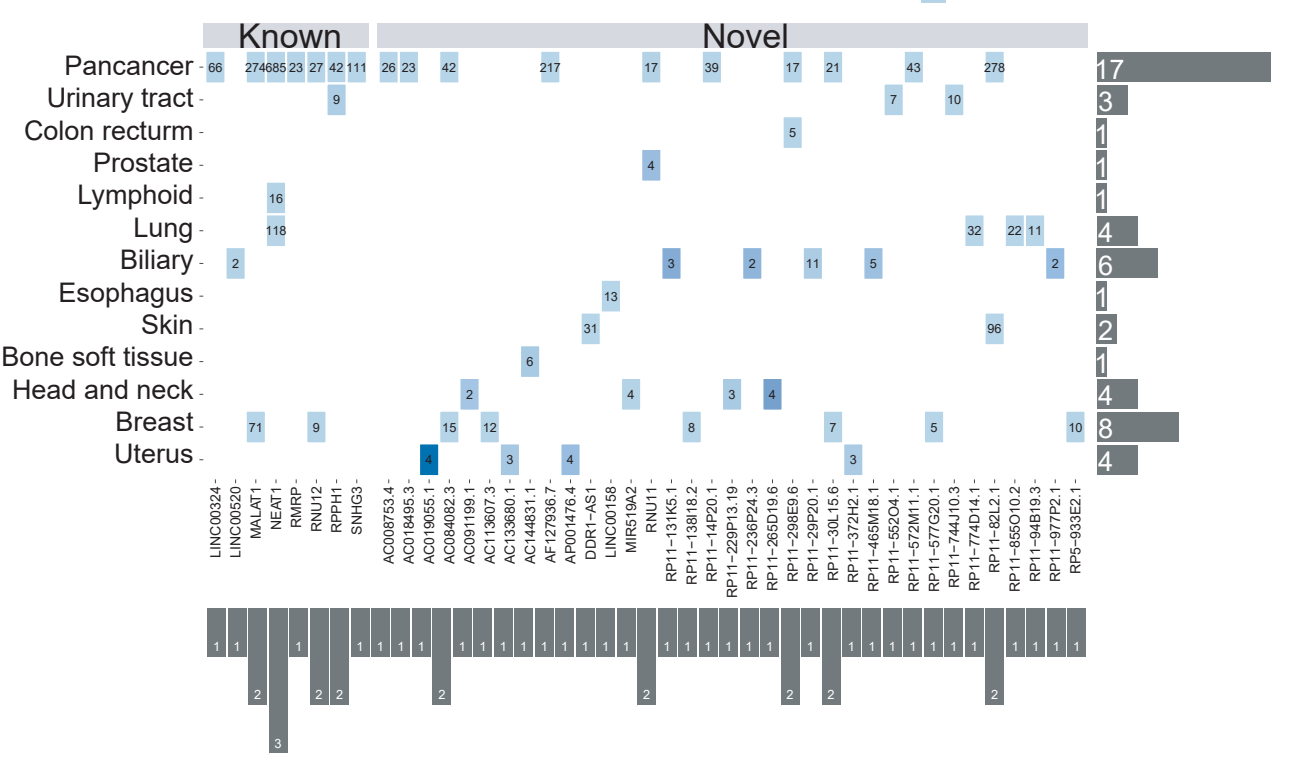

D

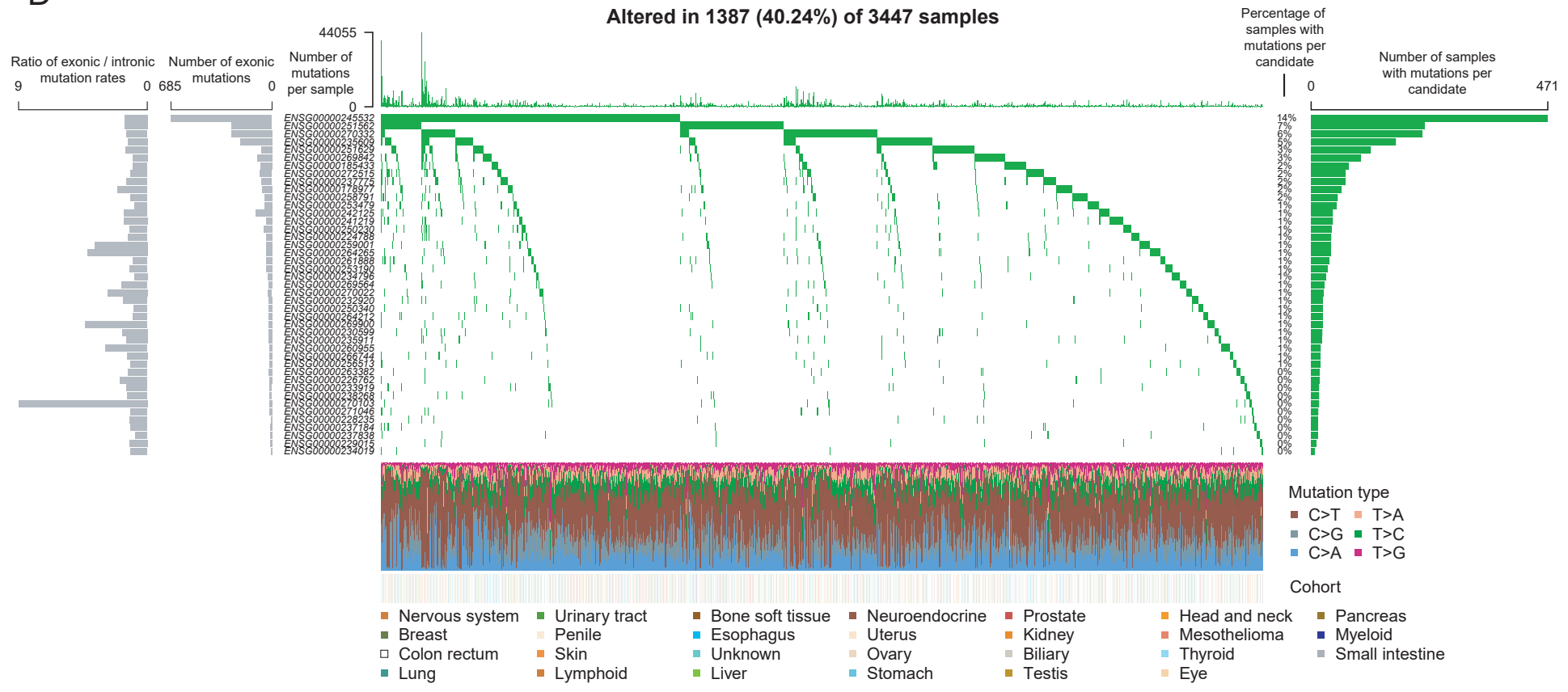


SupplenaieRter|pyefrigutree 5tps://doi.org/10.1101/2021.11.06.467555; this version posted January 11, 2022. The copyright holder for this preprint (which was not certified by peer review) is the author/funder, who has granted bioRxiv a license to display the preprint in perpetuity. It is made available under aCC-BY-NC-ND 4.0 International license.

A CRISPR-Cas9 mutational spectrum for Region 2

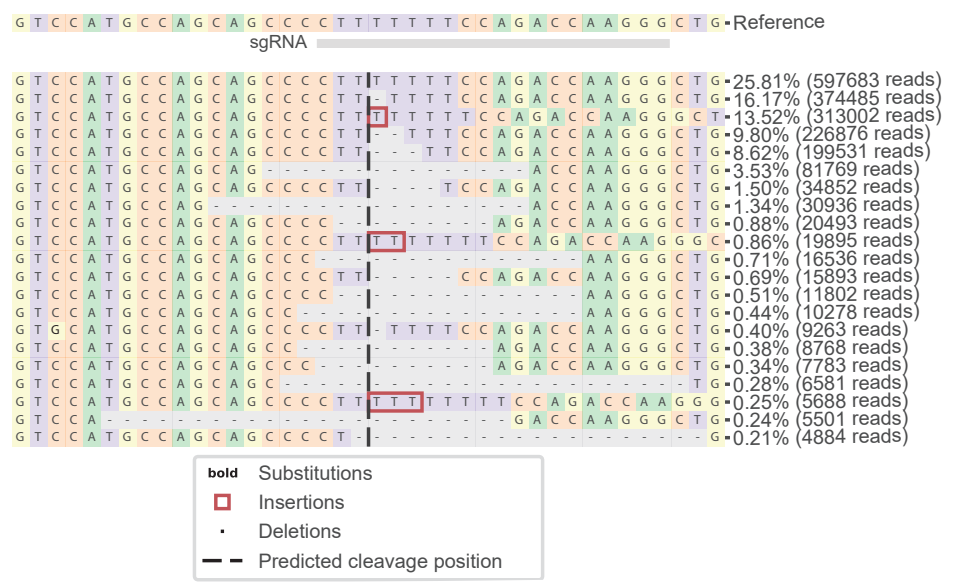

B NEAT1_1 genomic deletion using paired gRNAs

C Genomic fetures overlapping NEAT1, Region 2
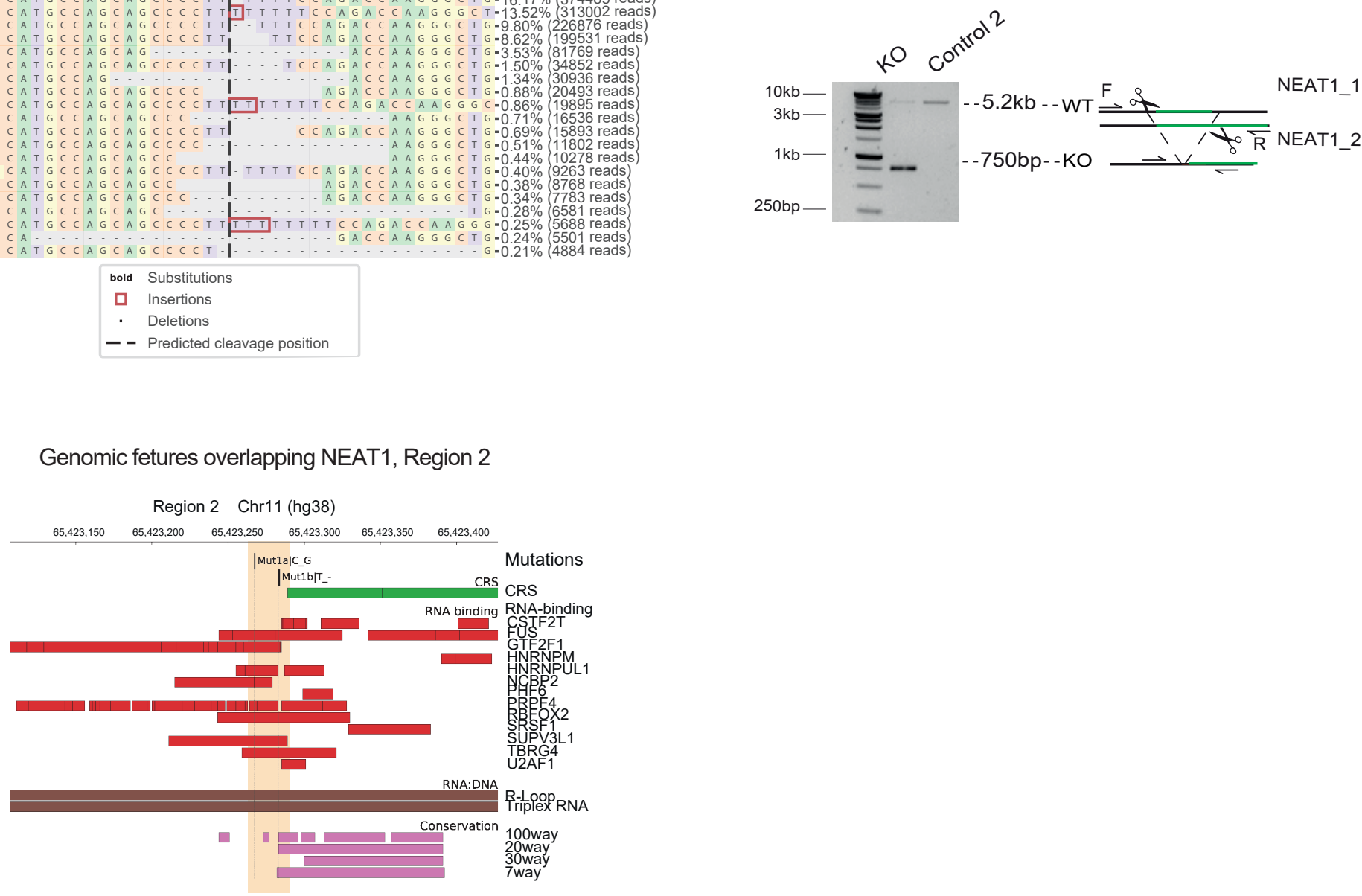